\title{
Consideraçóes sobre a cronologia de algumas mudanças na morfologia verbal do (galego)-português
}

\section{Changes in the verbal morphology of (Galician)-Portuguese: chronological considerations}

\author{
Maria José Carvalho \\ Universidade de Coimbra (Portugal) \\ mariac@fl.uc.pt
}

Recibido o 31/07/2018

Aceptado o 04/03/2019

\section{Resumo}

Neste artigo, estudaremos as cronologias das mudanças de alguns fenómenos relacionados com a morfologia verbal do (galego)-português, nomeadamente: (i) Particípios passados de verbos da $2 .^{\text {a }}$ conjugação; (ii) $\mathrm{O}-d$ - intervocálico no morfema número-pessoal de P5; (iii) Verbos incoativos em -ecer; (iv) Manutenção de $-e$ em formas de Presente do indicativo (com fonema pré-palatal no radical); (v) Mudanças de radical e regularização analógica na flexão de alguns verbos; (vi) Particípios fortes e truncados. O corpus usado consiste numa coleção documental constituída por 153 documentos notariais lavrados entre os séculos XIII e XVI, no mosteiro de Santa Maria de Alcobaça e seus coutos. Náo obstante reconhecermos que as cronologias náo coincidem simultaneamente para todos os fenómenos, mostrar-se-á que é possível estabelecer diferentes etapas evolutivas, com balizas cronológicas diferenciadas e delimitadas. Esta constataçáo aponta para a necessidade de se considerar a dimensão diacrónica quando se pretende comparar as línguas ibero-românicas atuais.

\section{Palavras-chave}

Periodização linguística, morfologia histórica, cronologia das mudanças morfológicas, morfologia verbal, regularização analógica

\section{Sumário}

1. Introdução 2. Análise do Corpus 2.1 Particípios passados de verbos da 2. a conjugaçáo 2.2. O morfema número-pessoal de $2 .^{\mathrm{a}}$ pessoa de plural 2.3 Irregularidades no paradigma verbal: verbos de padrão especial 2.3.1 Os verbos incoativos (des)perecer e merecer 2.3.2 Conhoscer, Conhocer e Conhecer 2.3.3 Pôr e Trazer: manutenção e apócope de -e 2.3.4 Alteração do radical (Trazer e Querer) 2.3.5 Pretérito perfeito do verbo Trazer 2.3.6 Pretérito perfeito do verbo (A)prazer 2.3.7 Futuro do indicativo do verbo Fazer (radical FA- / FAZ-) 2.3.8 Regularizaçáo analógica no verbo Perder 2.3.9 A primeira pessoa do Presente do indicativo do verbo Seer 2.4 Particípios fortes e truncados. 3. Conclusôes.

\section{Abstract}

The article examines the chronology of changes in some phenomena related to (Galician)-Portuguese verbal morphology, specifically: i) Past participles of 2nd conjugation verbs; (ii) Intervocalic $-d$ - in the P5 person-number morpheme; (iii) Inchoative verbs ending in -ecer; (iv) Maintenance of - $e$ in forms of the Present indicative (with pre-palatal phoneme in the stem); (v) Changes in the stem and analogical regularisation in the inflexion of certain verbs; (vi) Strong and truncated participles. The corpus used is a collection of 153 juridical documents, dating from the 13 th to the 16th centuries, from the Monastery of Santa Maria de Alcobaça and its territories. Although the chronologies do not coincide simultaneously for all the phenomena, it is nevertheless possible to establish evolutionary stages with distinct chronological boundaries. The findings emphasise the need to consider the diachronic dimension when comparing current Iberian Romance languages.

\section{Key words}

Linguistic periodisation, historical morphology, chronology of morphological changes, verbal morphology, analogical regularisation.

\section{Summary}

1. Introduction 2. Analysis of the corpus 2.1 Past participles of 2 nd conjugation verbs 2.2 . The person-number morpheme of the 2 nd person plural 2.3 Irregularities in the verbal paradigm: verbs with special patterns 2.3.1 Inchoative verbs (des)perecer and merecer 2.3.2 Conhoscer, Conhocer and Conhecer 2.3.3 Pôr and Trazer: maintenance and apocope of -e 2.3.4 Change of stem (Trazer and Querer) 2.3.5 Past perfect of Trazer 2.3.6 Past perfect of (A)prazer 2.3.7 Future indicative of Fazer (stem FA- / FAZ-) 2.3.8 Analogical regularisation in the verb Perder 2.3.9 First person Present indicative of Seer 2.4 Strong and truncated participles 3. Conclusions. 


\section{Introdução}

$\mathrm{O}$ OBJETivo deste artigo é tentar estabelecer a cronologia de alguns fenómenos de mudança a nível da morfologia verbal do galego-português, a partir de um corpus notarial seriado cronologicamente. Aquele que usámos como fonte é constituído por 153 documentos originais, por nós transcritos (Carvalho 2017), pertencente à coleção Mosteiro de Alcobaça, 1. ${ }^{\mathrm{a}}$ e 2. ${ }^{\mathrm{a}}$ incorporaçôes, IAN/TT (Lisboa). Tipologicamente, abarca a chamada "documentaçáo notarial particular": emprazamentos, aforamentos, vendas, escambos, quitaçóes, sentenças, testamentos, etc.

Não obstante reconhecermos a importância das primeiras gramáticas enquanto obras de reflexáo por observadores da língua do tempo, cremos que as fontes primárias cruciais para o investigador da língua são os textos escritos da época.

Mesmo tendo consciência do caráter fragmentário e textualmente não diversificado de um corpus como o que analisámos, assim como o artificialismo que qualquer divisáo comporta, tentaremos indicar os termos a quo e ad quem de vários fenómenos de morfologia verbal e que se traduziram, a avaliar pela amostra analisada, em mudanças sistemáticas em determinadas épocas. Recordamos aqui o que a este propósito afirmámos em 2003:

Modern phenomena first appeared in distinctly ancient periods, and (...), conversely, archaic phenomena persisted in new forms into modern contemporary phases. Arising from this there are obvious consequences when defining the points a quo and ad quem in the boundary marks of linguistic periods: as it is so difficult to date them rigorously, since as has been observed (see Ali 1964:8) "linguistic changes do not depend on the calendar, nor the year when the century began or ended", we will have to work with relative criteria, which always refer to the social heterogeneity characteristic of any speech community (Carvalho 2003: 61).

$\mathrm{Na}$ verdade, é um facto incontestável para o historiador da língua que as cronologias não coincidem simultaneamente para todos os fenómenos, sendo necessário estar consciente de que qualquer corte cronológico que se realize sobre a sua história é completamente artificial, uma vez que a evolução linguística é uma constante e impercetível renovação. Assim, se em sincronia é difícil conceber cortes no espaço, em diacronia é, igualmente, difícil conceber a existência de cortes no tempo, mas cremos que é sempre possível estabelecer algumas balizas de separação mais ou menos longas do ponto de vista diacrónico, que possam contribuir para o estabelecimento da cronologia das mudanças morfológicas ${ }^{1}$.

1. Veja-se o que já foi apresentado sobre periodização (com base em fenómenos de mudança morfológica), em Carvalho (1996: 150-155; Carvalho 2002) e, de forma mais abreviada e em língua inglesa, (Carvalho 2003). 


\section{Análise do Corpus}

\subsection{Particípios passados de verbos da $2 .^{\text {a }}$ conjugação ${ }^{2}$}

É sabido que no português arcaico a terminação dos particípios passados dos verbos em -er era constituída pela vogal temática $u+d o$, que cedo começou a aparecer em variação com $i+d o$. Quanto à cronologia da substituição da terminação -udo por -ido, o estudo levado a cabo neste corpus confirma as conclusóes já extraídas em estudos anteriores por nós efetuados (Carvalho 1999-2000: 26-28), ou seja, é visível a delimitação de três grupos participiais com cronologias bem distintas:

(i) particípios de verbos cuja terminação está precedida de fonema alveolar, dental ou palatal: conheçudo 'conhecido', vendudo, 'vendido', por ex.. 13 lexemas verbais: 25 ocorrências de -ud-, 91 de -id-;

(ii) particípios cuja terminação está precedida de fonema fricativo labiodental ou bilabial, quer se trate de fonema oclusivo ou contínuo: auudo 'avido', sabudo 'sabido', por exemplo. 4 lexemas verbais: 44 ocorrências de -ud-, 13 de -id-;

(iii) particípios com duas vogais em hiato no infinitivo, resultantes de síncope de consoante intervocálica: (con)teudo, 'contido', leudo 'lido', proueudo, 'provido', por ex. 3 lexemas verbais: 169 ocorrências de -ud-, 1 de -id-.

Analisemos, em primeiro lugar, os particípios arcaicos do primeiro grupo:

(rre)q[ue]rudo (1414 Alv 76), côftrẽgudos (1304 Alc 10), coftrẽiudo (1307 Alp 13), côftrengudos (1304 Alc 10), efguarne f̧̧udas (1291 Alc 3), eftabeleçudos (1328 Alj 21), metudo (1329 Evo 22), soeftabeleçudo (1379 Alc 51, 2 v.), softabeleçud[os] (1379 Alc 51), softabeleçudos (1379 Alc 51), foeftabeleçudo (1328 Alj 21), tajuda (1419 MA 79), tanjuda (1383 Alj 53; 1452 MA 106; 1453 MA 107; 1455 MA 108), uẽduda (1337 Alc 27; 1399 MA 66), uẽdudas (1317 Alc 16; 1386 MA 56), uẽdudos (1375 MA 48), vendudas (1450 Alv 104), uendudo (1345 MA 33), venduda (1397 MA 63).

Vale a pena lembrar o que então afirmámos:

No século $\mathrm{xV}$ as terminações das formas deste tipo são já, de um modo geral, em -ido, sendo que, quando precedidas de fricativa palatal sonora /žl ou das oclusivas dentais (/t/ e /d/), perduram ainda até meados desse século, apesar de já terem um nítido sabor arcaico (Carvalho 1999-2000: 27).

2. Para uma visão de conjunto sobre o estado da questão sobre este tópico, veja-se Mariño Paz (2005: 795-797). 
A primeira inovação data, neste corpus, de 1388: cozido (1388 MA 58) e a verdade é que ao terminar o segundo quartel do século Xv, não obstante a escassez de ocorrências, a terminação -udo parece ter soçobrado ${ }^{3}$. A partir de 1450, reduz-se a tanjuda (precedido de fricativa palatal sonora), que se extingue em 1455: 1452 MA 106; 1453 MA 107 e 1455 MA 108. Apresentam-se a seguir os particípios inovadores:

atendido (1451 MA 105), coregidas (1528 MA 147), coregijda (1448 Alj 103, 2 v.), coregida (1456 MA 109), coregujda (1448 Alj 103, 3 v.), coregydas (1507 MA 139), corregidas (1453 MA 107), corregidao (1479 MA 124), cozido (1388 MA 58; 1452 MA 106), defconhoçidos (1436 Alf 93), metido (1471 MA 119; 1526 Ped 145, 2 v.), metidoo (1462 Mai 114; 1471 MA 119), metjdos (1532 Tur 149), metydo (1433 Ped 90; 1536 SC 151), metydos (1536 SC 150; 1541 Sal 152), mjtidos (1509 Ped 140), mjtydoo (1467 Mai 117), ofericida (1460 MA 113), rreq[u]irido (1526 Ped 145), rreq[u]iridos (1526 Ped 145), rreq[ue]ridos (1444 Alv 100), rreq[ue]rydo (1491 Alj 133, 3 v.; 1496 Sal 135), rrequerido (1565 Alc 153), rrequerydos (1519 MA 142), tãgida (1416 MA 78; 1489 MA 130; 1495 MA 134), tãgjda (1422 MA 82; 1425 MA 84; 1429 MA 88), tãgyda (1519 MA 142), tamgida (1529 MA 148), tangida (1405 MA 70; 1426 MA 85; 1459 MA 110; 1460 MA 112; 1465 MA 116; 1471 MA 119; 1478 MA 122; 1477 MA 121; 1478 MA 123; 1479 MA 124; 1482 MA 125; 1484 MA 126; 1485 MA 128; 1490 MA 131; 1500 MA 136; 1502 MA 137; 1505 MA 138; 1522 MA 144; 1527 MA 146; 1528 MA 147), tangyda (1507 MA 139), tragida (1442 SM 97, 2 v.), uẽdida (1482 MA 125), uẽdido (1478 MA 122; 1485 MA 128; 1519 MA 142), uẽdidos (1391 MA 59), uẽdjdos (1442 MA 98), uendidas (1460 MA 112), vẽdidas (1495 MA 134), vẽdido (1482 MA 125; 1502 MA 137), vẽdjdo (1532 Tur 149), vendida (1477 MA 121; 1478 MA 123; 1484 MA 126), vendidas (1495 MA 134), vendido (1465 MA 116; 1479 MA 124; 1500 MA 136, 2 v.; 1502 MA 137), vendjda (1462 Alj 115), vendjdo (1462 Alj 115) e vendydas (1507 MA 139, 2 v.).

Quanto ao segundo grupo, são as seguintes as abonaçóes de antigos particípios, encontradas na documentação:

auódos (1377 Alv 50), auudo (1329 Evo 22; 1430 Cós 89), auudos (1337 Alc 27; 1362 MA 44; 1363 MA 45; 1372 MA 47; 1375 MA 48; 1392 MA 60; 1397 MA 63; 1397 MA 64; 1399 MA 66; 1405 MA 70, 2 v.; 1408 MA 71; 1409 MA 72; 1410 MA 73; 1413 MA 75; 1416 MA 78; 1419 MA 79; 1422 MA 82; 1423 MA 83; 1428

3. Trata-se, assim, de uma situação linguística manifestamente mais inovadora do que aquela que apresenta o corpus de Ana Maria Martins, uma vez que, segundo Anabela Leal de Barros, «o primeiro particípio em -ido surge, no corpus completo editado por Martins, logo em inícios do séc. XIv [sic!], a Norte (1402: cometida; requerido; requeridos) (...). Para a regiáo de Lisboa, o conjunto dos textos que completam o corpus não oferece qualquer novidade, já que apresenta o primeiro particípio em -ido apenas em 1454 (tangida)». (Barros 2000: 101). 
MA 87; 1429 MA 88; 1442 MA 98; 1443 Alf 99; 1459 MA 111; 1460 MA 112; 1462 Alj 115), aundoo (1469 Cel 118), aúúdos (1356 MA 41; 1362 MA 43; 1450 Alv 104), aund[os] (1386 MA 56; 1388 MA 58; 1426 MA 85; 1440 MA 96; 1465 MA 116; 1482 MA 125), avud[os] (1452 MA 106; 1453 MA 107), deundof (1412 Ped 74), rrecebudo (1402 MA 67) e rrecebudos (1405 MA 70).

Indicam-se a seguir os particípios inovadores:

aujdo (1451 MA 105), aujd[oб] (1459 MA 110), avidos (1522 MA 144; $1527 \mathrm{MA}$ 146; 1528 MA 147), avyda (1536 SC 150), avyd[os] (1489 MA 130), deujdo (1482 MA 125), movida (1490 MA 131), recebydos (1491 Alj 132), rrecebidas (1388 MA

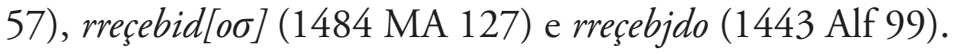

No trabalho de 1999-2000 concluímos que as variantes modernas do segundo grupo participial começam a propagar-se no segundo quartel do século Xv, generalizando-se nos últimos anos deste século. Ora, a primeira inovação neste corpus situa-se, tal como a do $1 .^{\circ}$ grupo, em 1388: rreçebidas (1388 MA 57), datando de 1482 a última ocorrência com terminação arcaica, ou seja, cerca de um século depois. $\mathrm{O}$ particípio aund[os] (1482 MA 125) foi, de facto, o que ofereceu mais resistência, o que confirma parcialmente a constatação que então fizemos:

Quanto a este grupo participial, as formas em -ido levam de vencida as antigas, na prosa literária do $2 .^{\circ}$ quartel do século $\mathrm{XV}$, com excepção dos particípios dos verbos aver $\mathrm{e}$ saber, que só começam a ceder (com mais celeridade o $2 .^{\circ}$ ) no $3 .^{\circ}$ quartel do século Xv, coabitando, em formulários diplomáticos, até ao fim do século com as antigas variantes (Carvalho 1999-2000: 27) .

A década de 80 surge, de facto, como uma década de célere mudança, tendo em conta que não se vislumbra qualquer indício da terminação em -udo a partir da data acima mencionada ${ }^{5}$. A situaçáo linguística dos documentos da região de Alcobaça é, assim, mais inovadora do que a apresentada pelo Tratado de Tordesilhas (1494), onde auidos coabita ainda com auudos (Maia 1994: 59-60 e nota 93).

4. Data de 1459 a primeira inovação, no particípio de auer, encontrada no corpus agora em análise: aujd[oo] (1459 MA 110).

5. Também neste grupo participial, há indícios de ter havido diferentes atitudes e valoraçôes da variante arcaica, ao longo do século Xv. Assim, na obra do rei D. Duarte, apenas se regista tymodo (no Livro da ensinança de bem cavalgar), e na Crónica de D. Fernando, de Fernão Lopes, apenas $28 \%$ dos particípios do grupo 2 são em -udo. Já na parte I da Crónica de D. João I, se os particípios em -udo do grupo 1 correspondem apenas a 1,7\% (sendo que, normalmente, surgem em discursos de personagens castelhanas), perduram os particípios antigos dos verbos aver, dever, mover, receber e saber, $85 \%$ dos quais correspondem às formas dos verbos aver e saber. Na parte II, os particípios deste grupo corres- 
Também Mariño Paz (2005: 806) é de opinião que «os testemunhos de CI [Crónica de Santa Maria de Iria], AP [Libro de notas de Álvaro Pérez, 1457], os documentos máis tardíos de HG-P [História do Galego-Português] e USC [Fontes documentais da Universidade de Santiago de Compostela] producen a sensación da que na segunda metade do século XV a mudanza estaria altamente consolidada no galego oral», observando, relativamente às fontes notariais consultadas, que "foi na primeira metade do $\mathrm{xV}$ cando esta experimentou un avance verdadeiramente notable que encontrou continuidade e desenvolvemento durante as décadas seguintes» (Mariño Paz 2005: 806).

Finalmente, do último tipo participial apenas possuímos uma forma inovadora bastante tardia: llydo (1541 Sal 152), o que não permite extrair conclusôes seguras quanto à cronologia do fenómeno, tanto mais que as formas de tipo arcaico são predominantemente do verbo teer e seu composto conter:

[cô]tehudo (1412 Ped 74), [cô]tehudas (1383 Alj 53, 2 v.; 1429 MA 88, 3 v.), [cô]tehudo (1383 Alj 53, 2 v.; 1422 MA 81), [cö]teudas (1336 Alj 26; 1350 AM 36; 1359 MA 42, 3 v.), [có]teudo (1350 AM 36; 1467 Mai 117), [cõ]theudas (1375 MA 48, 2 v.; 1386 MA 56, 2 v.; 1397 MA 63, 3 v.; 1397 MA 64, 2 v.; 1399 MA 66, 3 v.; 1403 MA 69, 3 v.; 1482 MA 125, 2 v.), [cô]theuda (1477 MA 121, 2 v.; 1478 MA 122, 2 v.; 1478 MA 123, 3 v.; 1479 MA 124, 4 v.; 1484 MA 126, 2 v.; 1485 MA 128, 3 v.), [cô]theudo (1421 Evo 80, 2 v.; 1443 Alf 99; 1477 MA 121; 1478 MA 122, 2 v.; 1482 MA 125, 2 v.; 1485 MA 128), [có]tiudas (1356 MA 41, 3 v.), [có]tíudo (1438 Ped 95, 2 v.), [con]tehudas (1423 MA 83; 1465 MA 116), [con]tehudo (1465 MA 116), [con]teudas (1409 MA 72, 2 v.; 1451 MA 105, 2 v.; 1490 MA 131, 3 v.), [con]teudo (1451 MA 105, 3 v.; 1460 MA 113, 5 v.; 1528 MA 147), [con]theuda (1426 MA 85), [con] theudas (1362 MA 44; 1363 MA 45, 3 v.; 1388 MA 58, 3 v. 1405 MA 70, 3 v.; 1408 MA 71; 1410 MA 73, 3 v.; 1413 MA 75, 3 v.; 1423 MA 83, 2 v.), [con] theudo (1391 MA 59; 1405 MA 70, 2 v.; 1462 Alj 115), [con]thiudo (1489 MA 130), [con]tjhudo (1435 Alj 92), comteudo (1515 SM 141; 1527 MA 146), comtheudas (1502 MA 137), conteudo (1336 Alj 26; 1437 Ped 94), conteudo (1522 MA 144), conthudo (1455 MA 108), contiudas (1452 MA 106, 2 v.), contiudas (1453 MA 107), contiudo (1452 MA 106), cótehudas (1416 MA 78; $1422 \mathrm{MA} \mathrm{82;1450} \mathrm{Alv} \mathrm{104),} \mathrm{cótehudo} \mathrm{(1355} \mathrm{Cel} \mathrm{40),}$ côteudas (1345 MA 33, 4 v.; 1541 Sal 152), côteudo (1304 Alc 10, 3 v.; 1317 Alc 16; 1321 Alc 17; 1330 Tur 23, 4 v.; 1334 Alf 25; 1336 Alj 26; 1343 AM 31; 1442 MA 98; 1496 Sal 135, 2 v.; 1519 MA 142), cótheud[oo] (1479 MA 124), cótheudas (1362 MA 44, 2 v.; 1375 MA 48), côthudas (1377 Alv 50), cótiudas (1362 MA 43, 3 v.), cótjudas (1419 MA 79), p[ro]ueudo (1402 MA 67), teudo (1345 MA 33; $1402 \mathrm{MA}$ 67, 2 v.), tẽudos (1297 Alc 5), teudos (1304 Alc 10, 3 v.), teudoo (1467 Mai 117, 2

pondem aos verbos atrever, aver, dever e saber, sendo igualmente arcaicos. Cerca de $82 \%$ correspondem igualmente aos verbos aver e saber. 
v.), theudo (1459 MA 111, 2 v.), theudos (1405 MA 70; 1459 MA 111, 2 v.) e tiud[os] (1453 MA 107).

Importa salientar que, não obstante o corpus de Ana Maria Martins ter apresentado uma situação linguística menos inovadora no que diz respeito aos particípios atrás analisados, «constata-se que surge pela primeira (e única) vez (...), em 1509, a terminação nova para o abundante verbo conter (contidas), em documento da cidade de Braga» (Barros 2000: 104). Por outro lado, «a regiáo de Lisboa, que em 1510 optava por tehudos, apresenta igualmente, e pela primeira vez nesse corpus, a forma alternativa (1540-“serão thidos e obryguados")» (Barros 2000: 105). De acordo com Mariño Paz (2005: 805), teudo é uma «relíquia do uso antigo fossilizada nunha determinada especialización semântica, e tanto en território galego coma en terra portuguesa».

Apresentam-se, esquematicamente, as linhas correspondentes ao desenvolvimento diacrónico dos três tipos participiais na coleção documental agora em estudo:

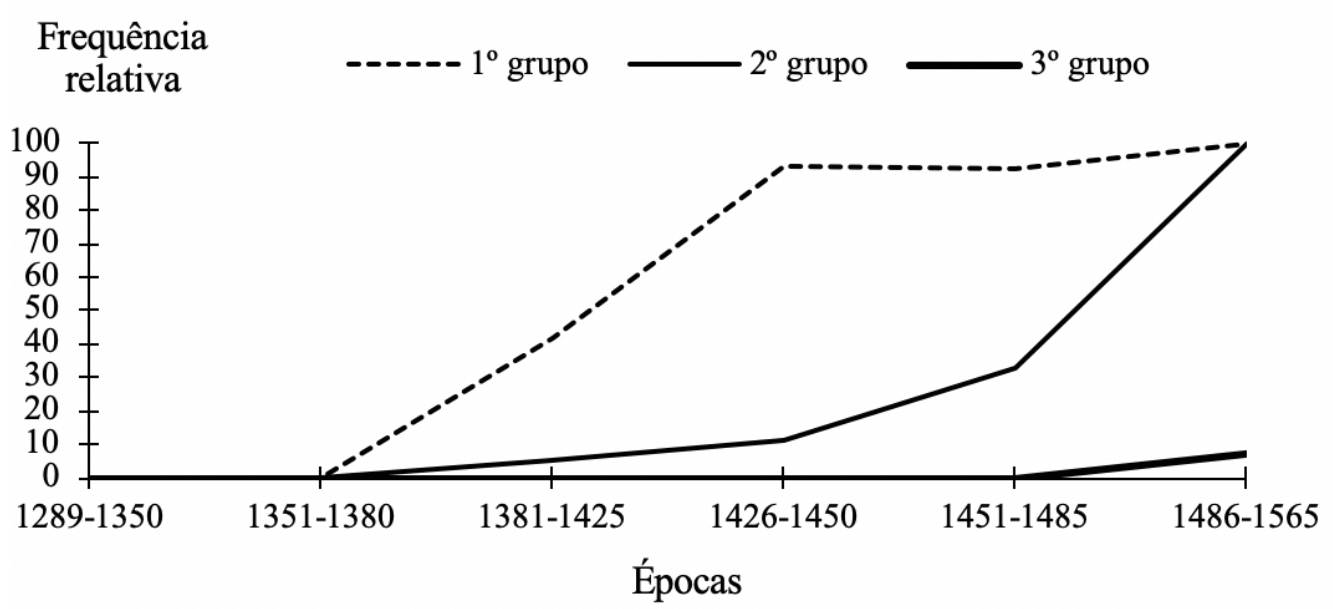

Figura n. ${ }^{\circ}$ 1. Evolução das terminações em -ido nos três grupos participiais, do século XIII ao século XVI

Comparando as linhas correspondentes ao desenvolvimento diacrónico neste corpus com as do mais extenso e diversificado, apresentadas em 1999-2000 (Carvalho: 24), concluímos que a mudança se operou de modo mais célere nos textos literários aí analisados, uma vez que as inovaçôes para os dois primeiros grupos participiais apresentam aí, já nos textos trecentistas, valores bastante superiores a 50\%. Por outro lado, se os valores das inovaçóes do primeiro e segundo grupos participiais caminham muito próximos nos textos literários, na prosa documental agora analisada verifica-se um grande distanciamento nos ritmos evolutivos. Este resultado é, certamente, devido ao facto de a esmagadora maioria dos particípios do segundo grupo pertencer, na prosa notarial, ao verbo auer. Também no $3 .^{\circ}$ grupo, a mestria literária de alguns 
autores (nomeadamente os poetas do Cancioneiro Geral) faz eliminar praticamente os particípios em -udo, ao passo que a prosa notarial os conserva pelo menos até meados do século XVI.

Quanto à situação linguística a norte do rio Minho, somos levados a concluir que a distância entre o oral e o escrito admitia, aí, eventualmente, um maior leque de matizes do que aquilo que nos evidenciam os textos da zona Centro-litoral, redigidos sob um modelo mais tradicional e, portanto, mais alheio ao que já estaria divulgado na oralidade. De facto, fatores de tipo diatópico, diastrático ou diafásico (nomeadamente estilísticos) poderáo ter, naquela área geográfica, acelerado este fenómeno. A este propósito, relembramos o que afirmámos em 1999-2000:

«A substituição da terminação participial arcaica -udo pela terminação -ido remonta a meados do século XIII, encontrando-se documentada, quer em fontes oriundas da Galiza (Lugo revela-se a província mais inovadora), quer em território português, e manifesta-se em todos os géneros textuais e em todo o tipo de verbos da 2. a conjugação. A proliferação de particípios modernos a partir de meados do século XIII atinge o seu apogeu nos Foros de Castelo Rodrigo, localidade pertencente ao antigo reino de Leão» (Carvalho 1999-2000: 406).

A análise dos resultados obtidos a partir de uma análise descritiva de frequência da Geral Estoria (onde $79 \%{ }^{6}$ dos particípios passados de verbos da 2. ${ }^{a}$ conjugação são em -ido) conduz-nos igualmente a aceitar a precocidade do avanço da variante inovadora, a norte do rio Minho. De acordo com Mariño Paz (2005: 799-800):

Xa desde as primeiras décadas do século XIv (cando se traducia para o galego a Geral Estoria, GE), a variante -id[o(s), a(s)] para os particípios regulares da CII e do verbo vñir e derivados debía de ser unha opción solidamente instalada no romance galego, especialmente - supoño - en certas variedades da língua que actualmente non podemos identificar. Os autores e/ou tradutores de HT [Historia Troyana] e de CI extremarían a preferência por esta variante que xa se advirte en GE, mentres que os de TC [ La traducción gallega de la Crónica General y de la Crónica de Castilla], CT [Crónica Troiana] e MS [Os Miragres de Santiago] se decantarían com sensible diferenza pola variante antiga $-u d[o(s), a(s)]$.

O que, na nossa opinião, deverá ter acontecido, a avaliar pela situação linguística dos Foros de Castelo Rodrigo bem como da traduçáo galega da General Estoria,

6. Marińo Paz (2005: 799, n. 7) refere, todavia, a percentagem de 77, 75\%. A divergência existente entre os dois valores não é, de facto, significativa e poderá dever-se a falha humana, de programação, ou ainda à «fluidez com que alguns verbos circularon entre a CII e a CIII ao longo da historia da língua galega» (2005: 798). Na verdade, como evidencia o Autor galego (2005: 798), pode haver verbos que oscilam entre o paradigma de $2 .^{a}$ e de $3 .^{a}$ conjugaçáo (nomeadamente, repentirl-(se), remiir e changer). 
foi a aceitação e a divulgação inicial deste fenómeno inovador, em todos os níveis sociolinguísticos, e em toda a região do Noroeste peninsular (aquém e além Minho). Progressivamente, com a gradual formação da consciência linguística dos falantes bem como da atuação de modelos linguísticos emanados das elites culturais e dos centros de poder, constituiu-se uma espécie de "filtro de seleção" que teve por base as restriçóes fonéticas mencionadas. De um modo geral, esse período de seleção não foi muito longo (neste fenómeno concreto, durou pouco mais de meio século) mas houve contextos (como o de vizinhança de consoante labial ou a existência de duas vogais em hiato) que continuaram a oferecer alguma resistência à mudança.

\subsection{O morfema número-pessoal de $2 .^{\mathrm{a}}$ pessoa de plural $^{7}$}

Como se sabe, as formas em - des ou -de (no imperativo), resultado da evolução fonética do sufixo latino -tis ou -te, irão sofrer, no português, o processo de desaparecimento do $d$ intervocálico, que irá desencadear as regras assimilatórias subsequentes. A simplificação das vogais em contato e a formação da semivogal (cantedes $>$ cantees $>$ cantes $>$ canteis; cantades $>$ cantaes $>$ cantais) são, pelo menos na escrita, mais tardias, revelando este último processo um resultado já semelhante ao português contemporâneo bem como ao que apresentam as formas de imperativo mais atestadas no galego contemporâneo: «no imperativo a solución mais atestada nas fontes posmedievais non foi na CI e na CII a que transitou pola vía da asimilación e a crase vocálica (con cantá e collé, formas análogas de cantás e collés), senón a da disimilación e a xeración de ditongo decrecente (con cantai e collei) (Mariño Paz 2016: 158). Diferente é, como se sabe, a situação do galego atual relativamente a todas as restantes formas dos outros tempos e modos verbais, onde este fenómeno «só parcialmente se resolveria nos últimos dous séculos cun movimento tendente a impoñe-las formas com mantimento do - $d$-, hoxe maoritarias» (Mariño Paz 1992: 79).

Quando, em 1996, fornecemos os dados para a cronologia deste fenómeno na documentaçáo régia, privada e eclesiástica do século xv, acrescentámos em nota:

À falta de um estudo sistemático feito a partir da documentação privada da zona centro-meridional (que, por escassez de fontes, não pudemos empreender), esta confrontação de dados revela-se, de alguma forma, incompleta. De facto, seria interessante incluir na tabela os resultados de um estudo aprofundado da documentação de outra origem geo-sociolinguística, uma vez que a documentação aqui analisada pertence, na sua grande maioria, às chancelarias régias. Sendo assim, a comparação entre a situação do fenómeno na zona da Galiza, do Minho e das áreas Centro e Sul do país desvirtua-se,

7. Trata-se de um fenómeno já analisado na nossa dissertação de Mestrado (Carvalho 1996: 35-74). Veja-se, igualmente, Carvalho (2000; 2011). 
na medida em que se colocam lado a lado "idiolectos" (e "sociolectos") diferentes (Carvalho 1996: 48 e nota 1).

Pretende-se fornecer, com o corpus sob análise, mais alguns dados que permitam colmatar essa então "lacuna" da nossa pesquisa. De facto, a última pesquisa sobre este fenómeno em território galego veio evidenciar que a primeira forma com síncope de - $d$ - de que temos notícia localiza-se numa escritura notarial de 1275: parés 'paredes' (Mariño Paz 2014: 281), relativamente coeva da forma (também com crase) condapnes, contida na versão galego-portuguesa do compêndio legislativo Flores de Dereyto (Carvalho 2000: 66), eventualmente elaborada na corte de D. Dinis. Daqui decorre que a inovação se poderá ter verificado em qualquer região e nível sociolinguístico.

Assim, na coleção alcobacense agora em estudo, o morfema número-pessoal é invariavelmente - des até 1450, o que revela, se compararmos essa situaçáo com a que apresentam outras "línguas funcionais" ${ }^{8}$, nomeadamente as das variadas chancelarias régias ou as dos textos de natureza técnica e moralística (Livro da Ensinança de bem cavalgar, Virtuosa Benfeitoria e Leal Conselheiro), um considerável conservadorismo, justificado pelo peso que a configuração morfológica latina impunha neste tipo de prosa, ou pela simples inércia à atualização da inovação. Data de 1451 , no corpus agora em apreço, o primeiro documento a revelar os primeiros exemplos de síncope de $-d-$, pelo que apresentamos, na tabela seguinte, as ocorrências registadas a partir daí bem como a sua representatividade no interior do documento em causa:

\begin{tabular}{|c|c|c|c|}
\hline Documento & SÍNCOPE DE -d- & CONSERVAÇÃo DE -d- & \% (SÍNCOPE) \\
\hline 1451 MA 105 & facaaes; fazeelhe & uendedelhe & 67 \\
\hline 1452 MA 106 & $\begin{array}{l}\text { ajaaes; farees; rrefa- } \\
\text { rees; avees; tenhaaes; } \\
\text { gua[r]des; pofaaes }\end{array}$ & $\begin{array}{l}\text { ap[ro]ueitedes; arronperedes; plan- } \\
\text { t(a)redes; faredes; rrefaçedes; daredes; } \\
\text { comecaredes; averedes; dedes; pagedes }\end{array}$ & 41 \\
\hline 1453 MA 107 & ajaaes; pofaaes, $2 \mathrm{v}$. & 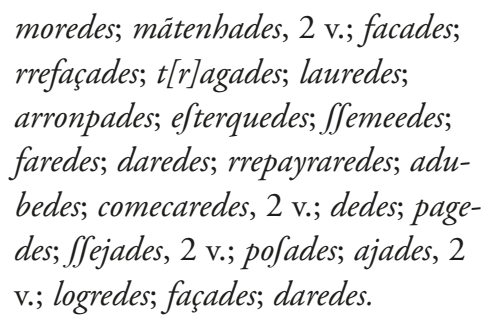 & 10 \\
\hline 1460 MA 113 & $\begin{array}{l}\text { Joes; [con]p[r]ifeis; } \\
\text { executafeis; façaaes; } \\
\text { fazeelhe }\end{array}$ & & 100 \\
\hline
\end{tabular}

8. Referimo-nos a outros tipos textuais já percorridos, aquando da elaboração da nossa tese de mestrado (textos técnicos, literários, prosa dos documentos das chancelarias régias, etc.). Se compararmos esta situaçấo com a da primitiva área galego-portuguesa, concluímos que é bastante mais inovadora. 


\begin{tabular}{|c|c|c|c|}
\hline Documento & SÍNCOPE DE -d- & Conservação de -d- & $\%$ (SíNCOPE) \\
\hline 1465 MA 116 & $\begin{array}{l}\text { viuees; farees; ajaaes; } \\
\text { pofaaes }\end{array}$ & 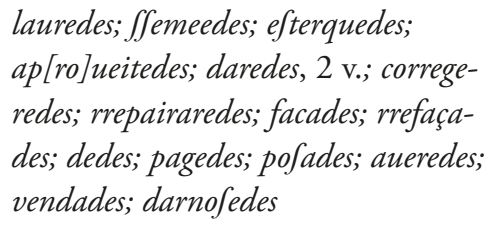 & 20 \\
\hline 1469 Cel 118 & & 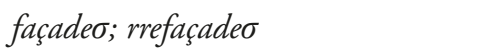 & 0 \\
\hline 1472 TC 120 & $\begin{array}{l}\text { jntronjzees; metaaes; } \\
\text { facaaes; defendaaes }\end{array}$ & & 100 \\
\hline 1478 MA 122 & & 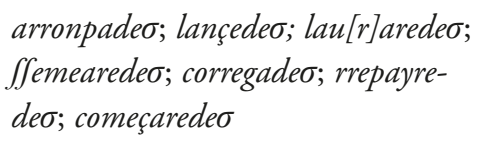 & 0 \\
\hline 1491 Alj 132 & darees & & 100 \\
\hline $1491 \mathrm{Alj} 133$ & $\begin{array}{l}\text { fooees; p[ro]çedees; } \\
\text { dees, } 2 \mathrm{v} .\end{array}$ & & 100 \\
\hline 1515 SM 141 & mädes; mandes & & 100 \\
\hline
\end{tabular}

Tabela n. ${ }^{\circ}$ 1. Variação entre formas verbais com conservaçáo e síncope de - $d$-, registada a partir de 1450

A observação da tabela permite-nos concluir que a variação entre formas plenas e sincopadas se verificou entre 1450 e eventualmente cerca de 1480 , devendo apontar-se a década de 80 como a época da verdadeira mutação linguística. Durante esse período, a oscilação é patente no interior do texto de uma mesma pessoa, o que faz prever a coexistência de formas conservadoras e inovadoras; há, contudo, indícios de que um mesmo indivíduo poderia manifestar uma evolução linguística no espaço de 9 anos. Se nos lembrarmos que os documentos 1451 MA 105 e 1460 MA 113 pertencem à mesma mão («Diego Afomfo efcripuâ»), que emprega em 1451, ao lado de facaaes e fazeelhe, a forma mais antiga uendedelhe, e em 1460 opta por cinco formas verbais sincopadas: foes, [con]prifeis, executa]eis, façaaes e fazeelhe, podemos concluir que o tabelião teria entretanto desistido de usar as formas arcaizantes, por as considerar como tais ou por pressão dos usos orais.

$\mathrm{Na}$ verdade, deverá admitir-se que deve ter existido uma correlação entre variação morfológica e o fator idade/tempo, fazendo prever, por isso, um tipo de variação diastrática. As diferentes soluçóes para a resolução do hiato nas terminaçóes -aes e -ees acompanharam o advento da síncope de $-d$ - . Assim, por exemplo, nas formas de verbos cuja manifestação de modo e tempo é - $a-$ ou - - , ainda que graficamente o ditongo não se evidencie, grafias ultracorretas, com geminação gráfica dessa vogal (ou, por vezes, também da vogal do morfema de número-pessoa) como facaaes, ajaaes, tenhaaes, pofaaes, metaaes, defendaaes e fooees provam a falta de controlo gráfico que o ditongo resultante da passagem da vogal da desinência número-pessoal a semivogal provocava na escrita. Quanto aos verbos com morfema modo-temporal -e-, uma das soluçóes encontradas foi a crase das duas vogais em contato (dos morfemas modo-temporal e 
número-pessoal), registada já em 1452: guardes ('guardeis') e, como solução única, no século XVI: mädes e mandes ('mandeis') ${ }^{9}$. Curiosamente, as formas provenientes de proparoxítonas [con]prifeis e executa/eis, situadas em 1460, confirmam (não obstante o seu carácter isolado), as conclusóes por nós apresentadas em 1996: «no terceiro quartel do século XV apresentam, todavia, uma grande propensão para a formação do ditongo, ao contrário do que ocorre na língua castelhana, onde este tipo de formas preservou até mais tarde o - $d$-» (Carvalho 1996: 73).

Curiosamente, uma comparação com a situação linguística dos textos congéneres da zona galega permite concluir que a inovação deverá ter tido o mesmo ritmo evolutivo. Segundo Mariño Paz, «En galego as documentacións desta innovación, raras aínda nas fontes do século XIV e da primeira metade do XV, gañan frecuencia a partir de 1451, ainda distando moito de se faceren maioritárias no conxunto do corpus dispoñible» (Mariño Paz 2014: 261).

O que se terá verificado, na nossa opiniáo, foi uma tendência para a estigmatização de - $d$ - intervocálico na zona Centro-litoral portuguesa, ao contrário do que se passava a norte do rio Minho. Basta lembrar a forma leixadeos que surge na Crónica de D. João I, de Fernão Lopes, na boca da "aleivosa", personagem que inspira antipatia ao Povo, ou, ainda, as de outra personagem feminina, em cenário doméstico (leixade e $j d e^{10}$ ), para compreendermos o alcance da escolha deste marcador morfológico na avaliação da condição feminina da época (Carvalho 2000: 70). Em ambos os casos, as formas verbais com - $d$ - surgem isoladas nas duas partes da Crónica, o que nos leva a concluir sobre a sua intencionalidade e, por conseguinte, a consciência linguística que teria um autor da segunda metade do século XV.

Em território galego, «en puntos ilados do sur da provincia da Coruña, oeste de Lugo, nordeste de Pontevedra e noroeste de Ourense mantéńense, sobre todo na fala dos vellos, as solucións cantás, cantarés, etc., se ben esporadicamente e alternando coas formas plenas» (Mariño Paz 1992: 85). Segundo o Autor galego, «en amplas zonas do nosso território [galego] case tódolos falantes, na súa liberdade como usuários da língua, preferiron rexeitar - non adoptar - a innovación, que producía un sistema "desequilibrado", e mantiveron as formas tradicionais» (Marińo Paz 1992: 91). Em Portugal, as formas com -des/-de permanecem apenas em algumas variedades socioletais da Beira Alta ${ }^{11}$ e na zona fronteiriça de Trás-os-Montes.

9. Não temos dados, para o português, que permitam comparar quantitativamente as soluçóes -is e -s na prosa notarial para além do século xvi. De acordo com Mariño Paz, «a innovación -s, logo de experimentar un importante proceso de difusión que a colocou como a variante máis atestada nas fontes do galego medio, iniciou nos últimos tempos un acusado retrocesso» (2014: 283).

10. Ao contrário do que acontece atualmente, esta forma nunca mantém o-d-, nas Crónicas de Fernão Lopes.

11. Ainda recentemente ouvi uma forma em -ndes (estandes), a um falante de género feminino, com 74 anos de idade e pouca escolaridade, no concelho de Pinhel. Segundo Mariño Paz, a variante -nde 


\subsection{Irregularidades no paradigma verbal: verbos de padrão especial ${ }^{12}$}

Analisaremos as cronologias dos processos de regularização dos paradigmas verbais (em muitos casos decorrentes do nivelamento analógico) naqueles verbos em que os dados permitiram tecer algumas consideraçóes: (des)perecer, merecer, conhoscer, pôr $r$ querer, trazer, aprazer, fazer, perder, seer.

\subsubsection{Os verbos incoativos (des)perecer e merecer}

Os verbos incoativos em -ecer (<-ESCĔRE) apenas mantêm a terminação etimológica (neste caso, no Presente do conjuntivo) durante o século XIV, localizando-se a última abonação em 1391. A partir do século xv, já só se documentam nesta coleção aquelas que apresentam uma configuração idêntica às formas modernas do galego e do português. Em 1388, por exemplo, um documento evidencia $p[e r] e \int c a$ e $p[e r] e f c a m$, enquanto que um outro do mesmo ano já apresenta a forma conhoço, como veremos a seguir. Apresentam-se, na tabela seguinte, os dados colhidos no nosso corpus para as formas sob epígrafe:

\begin{tabular}{|c|c|c|c|}
\hline \multicolumn{2}{|c|}{ TERMINAÇÕES ETIMOLÓGICAS } & \multicolumn{2}{|c|}{ TERMINAÇÓES MODERNAS } \\
\hline Documentos & Formas & Documentos & Formas \\
\hline 1304 Alc 9 & defperefcä; defperefcam & & \\
\hline 1313 Tur 14 & $m[e r] e \int c a m$ & & \\
\hline 1388 MA 58 & $p[e r] e \uparrow c a ; p[e r] e \varsigma c a m$ & & \\
\hline \multirow[t]{9}{*}{1391 MA 59} & $p[e r] e \int c a m$ & & \\
\hline & & 1405 MA 70 & pereça \\
\hline & & 1452 MA 106 & pereçã \\
\hline & & 1453 MA 107 & pereça, $2 \mathrm{v}$. \\
\hline & & 1459 MA 110 & p[er]eça \\
\hline & & 1478 MA 123 & p[er]eçam \\
\hline & & 1479 MA 124 & $p[e r] e c ̧ a \tilde{a}$ \\
\hline & & 1495 MA 134 & perecam \\
\hline & & 1507 MA 139 & perę̧am \\
\hline
\end{tabular}

Tabela n. ${ }^{\circ}$ 2. Cronologia das terminaçóes etimológicas e modernas nos verbos incoativos (des)perecer e merecer

«rexistrou-se só no suroeste pontevedrés e no sur e leste de Ourense» (Mariño Paz 2016: 150).

12. Para a questão das terminaçôes nasais nas formas verbais de $3 .^{a}$ pessoa do plural, veja-se o que foi possível apurar em Carvalho (2013). 
Trata-se, como se vê, de uma situação linguística mais inovadora do que a que apresentam os documentos transcritos por Clarinda Maia. De acordo com esta autora, «num documento do início do século Xvi surge já a forma enpeça (1516 C 18)» $\left(1997^{2}: 732\right)$. Depreende-se, portanto, que não foram encontradas abonaçóes deste tipo antes desta data.

\subsubsection{Conhoscer, Conhocer e Conhecer}

Ao contrário do que se verifica na coleção documental publicada por Maia, onde todas as ocorrências deste lexema apresentam como última vogal do radical $o$ etimológico, a alteração desta vogal nas formas flexionais e derivadas de conhoscer/conhocer começa a registar-se no século XIV, generalizando-se no segundo quartel do século XV. O último exemplo da forma incoativa (com -SC-) data de 1399, tornando-se a mudança sistemática a partir dessa altura. Quanto às formas com $o$ etimológico sem dissimilação vocálica, é de 1456 o último documento que encontrámos com esse tipo de testemunho. Os dados colhidos encontram-se sistematizados na tabela seguinte:

\begin{tabular}{|c|c|c|c|}
\hline Docs. & VARIANTES ANTIGAS & Docs. & VARIANTES MODERNAS \\
\hline 1291 Alc $2 ; 1291$ Alc 3; 1299 Alc 7 & conhofcam & & \\
\hline \multirow[t]{2}{*}{1298 Alc 6} & $c o[n] h o \int c a \tilde{a}$ & & \\
\hline & & $1315 \mathrm{Alj} 15$ & conheçęça \\
\hline \multirow[t]{2}{*}{1321 Alc 17} & conhocimẽto & & \\
\hline & & 1375 MA 49 & [co]nhẽço \\
\hline 1388 MA 57 & conhoço & & \\
\hline 1391 MA 59 & conhocimẽto & & \\
\hline \multirow[t]{2}{*}{1399 MA 65} & $\operatorname{conho} \int \mathrm{co}$ & & \\
\hline & & 1428 Alj 86 & $\begin{array}{l}\text { conhjçmẽto, } 3 \mathrm{v} . ; \\
\text { conhjçja }\end{array}$ \\
\hline \multirow[t]{2}{*}{1436 Alf 93} & $\begin{array}{l}\text { conhoçiä; defconhoçi- } \\
\text { dos; conhoçiam }\end{array}$ & & \\
\hline & & 1440 MA 96 & conheçiment[os] \\
\hline \multirow[t]{8}{*}{1456 MA 109} & rreconhoçjä & & \\
\hline & & 1462 Mai 114 & conheciam \\
\hline & & 1467 Mai 117 & conhiçim [ẽ]to \\
\hline & & 1469 Cel 118 & conbeço \\
\hline & & 1491 Alj 133 & conhecer, 2 v. \\
\hline & & 1509 Ped 140 & conheçerã \\
\hline & & 1521 Ped 143 & conheçerã \\
\hline & & 1565 Alc 153 & conheçim[ẽ] to \\
\hline
\end{tabular}

Tabela n. ${ }^{\circ}$ 3. Cronologias de conhoscer, conhocer e conhecer (e derivados) 


\subsubsection{Pôr e Trazer: Manutenção e apócope de -e}

Os documentos da regiấo em estudo registam, na primeira pessoa do Pretérito perfeito do verbo poer (com vogal $u$ no radical motivada pela metafonia), a manutenção da vogal final em todas as ocorrências registadas ${ }^{13}$ :

puge (1355 Cel 40), puggi (1306 Cós 12), pugi (1304 Alc 10), pugi (1336 Alj 26), pugj (1305 Alp 11; 1307 Alp 13; 1328 Alv 20; 1329 Evo 22; 1330 Tur 23; 1334 Alf 25; 1338 Alv 28; 1340 Ped 29; 1343 AM 31; 1346 SC 34; 1346 Tur 35), pugy (1326 MA 19) e puffy (1299 Alc 7).

Recorde-se que a forma portuguesa atual é pus, com palatal sonora no radical, ao passo que no galego atual é puxen, com palatal surda. Diz-nos Varela Barreiro que, «de par do xeral pux-consérvase na Limia Baixa en todo o tema de perfecto o radical palatal sonoro [puz-]. (...) Mais interesse encerra o sistema da área zamorana, que presenta radical sibilante non palatal en todo o tema de perfecto ([pus-])». Para o Autor, «o radical pus- é a conservación do modelo medieval nunha zona marcadamente caracterizada como conservadora e arcaizante, nunha zona que por estar illada permaneceu inexpugnable à penetración das innovacións que lle viñan do oeste e tamén do leste» (Varela Barreiro 1999: 1064-1065).

Por outro lado, na terceira pessoa do presente do indicativo do verbo trager ${ }^{14}$, verifica-se uma mudança (apócope de $e$, com alteração gráfica da palatal), a partir do século XV:

13. Uma vez que a partir de meados do século xIV a expressão "pôr um sinal» vai ser substituída por «fazer um sinal», esta forma verbal é substituída a partir daí por $f i z$, sempre apocopada, ao contrário do que se verifica nos documentos galegos publicados em História do galego-Português (Maia 1997²: 733 e 745). Também «Nos documentos da zona portuguesa surgem sempre formas com $i$ na sílaba tónica, mas já não se encontram vestígios da vogal final» (Maia 1997²: 745).

14. Discordando de outros autores (nomeadamente, de Adolfo Coelho), Leite de Vasconcellos crê que esta forma se pronunciava traguer (tragher), e náo trajer (Vasconcellos 1890-1892a: 270). Varela Barreiro opta, para o galego moderno (dos Séculos Escuros), pelo lema traer e não por trager pois, apesar de ser esta a única forma de Infinitivo documentada durante esse período, representa, segundo o Autor, um estado anterior da língua (Varela Barreiro 1999: 1060). 


\begin{tabular}{|c|c|c|c|}
\hline \multicolumn{2}{|c|}{ VARIANTES ANTIGAS } & \multicolumn{2}{|c|}{ VARIANTES APOCOPADAS } \\
\hline Documentos & Formas & Documentos & Formas \\
\hline $1304 \mathrm{Alc} 10$ & trage & & \\
\hline 1362 MA 44 & trage, $2 \mathrm{v}$. & & \\
\hline \multirow[t]{8}{*}{1375 MA 48} & trr]age & & \\
\hline & & 1416 MA 78 & $\operatorname{traz}, 5 \mathrm{v}$ \\
\hline & & 1423 MA 83 & traz \\
\hline & & $1447 \mathrm{Alj} 101$ & $t[r] a z, 2 \mathrm{v}$. \\
\hline & & $1482 \mathrm{MA} 125$ & $\operatorname{traz}, 2 \mathrm{v}$ \\
\hline & & 1484 MA 126 & $t[r] a z$ \\
\hline & & 1485 MA 128 & $t[r] a z$ \\
\hline & & 1489 MA 130 & $t[r] a z$ \\
\hline
\end{tabular}

Tabela n. ${ }^{\circ}$ 4. Variantes antigas e apocopadas das formas de $3 .^{a}$ pessoa do Presente do indicativo do verbo trazer

\subsubsection{Alteração do radical (Trazer e Querer)}

Ao contrário do que se verifica em História do galego-português, onde «não se encontrou nenhum vestígio de formas correspondentes à forma moderna do infinitivo português trazer» (Maia 1997²: 842), o corpus que analisámos revela que na zona Centro-meridional a nova variante se tornou dominante a partir do século XV, apesar de esporadicamente se encontrar tragida, num texto de origem periférica (S. Martinho), do segundo quartel desse século. Data de 1414 a primeira variante moderna registada, como se pode verificar:

\begin{tabular}{|c|c|c|c|}
\hline Documentos & Formas & Documentos & Formas \\
\hline 1340 Ped 29 & $t[r a] \operatorname{gia} a$ & & \\
\hline 1343 AM 31 & $\operatorname{tragem}[0 s], 3 \mathrm{v}$ & & \\
\hline 1359 MA 42 & $t[r] a \boldsymbol{g}[e r]$ & & \\
\hline $1362 \mathrm{MA} 43$ & trr]agia & & \\
\hline \multirow[t]{2}{*}{1379 Alc 51} & t[r]aier & & \\
\hline & & $\begin{array}{l}1414 \text { Alv } 76 \\
1430 \text { Cós } 89\end{array}$ & $\begin{array}{l}t[r] a z j a \tilde{a} \\
\text { trazja }\end{array}$ \\
\hline \multirow[t]{4}{*}{1442 SM 97} & tragida & & \\
\hline & & 1444 Alv 100 & $t[r] a z i a$ \\
\hline & & 1450 Alv 104 & t[r]azia \\
\hline & & 1455 MA 108 & trazia \\
\hline
\end{tabular}




\begin{tabular}{|c|c|c|c|}
\hline Documentos & Formas & Documentos & Formas \\
\hline & & 1459 MA 110 & t[r]azija \\
\hline & & $1462 \mathrm{Alj} 115$ & trazya \\
\hline & & 1479 MA 124 & t[r]azem \\
\hline & & 1485 MA 128 & t[r]azer \\
\hline & & 1489 MA 130 & $t[r] a z i a, 2 \mathrm{v}$. \\
\hline & & 1495 MA 134 & $t[r] a z i a$ \\
\hline & & 1500 MA 136 & $t[r] a z i a$ \\
\hline & & 1505 MA 138 & $t[r] a z e \tilde{e} d ;$; $t[r] a z i a ; t[r] a z e r, 2 \mathrm{v}$. \\
\hline & & 1527 MA 146 & trazia \\
\hline & & 1565 Alc 153 & trazia \\
\hline
\end{tabular}

Tabela n. ${ }^{\circ}$. Variantes antigas e modernas das formas do verbo trazer

Tendo em conta o carácter tardio da referida forma, adquire consistência a hipótese colocada por Clarinda Maia, ao admitir que:

trazer seja uma forma criada já dentro do português a partir de trager, em virtude da evolução bastante frequente de [ž] intervocálico a $[\mathrm{z}]$. Desse modo, a nova forma do infinitivo ter-se-ia aproximado de outros infinitivos com idêntica configuração fonética, tais como fazer, prazer (...) (Maia 1997²: 844-845).

Relativamente às formas provenientes da série de Perfeito formadas a partir de QUÆSĪ, todas revelam não só a apócope de i/e final como a evolução do radical com sonorização de fricativa ápico-alveolar -S- (grafado com -z-). A única exceção, neste corpus, diz respeito à forma antiga da série do perfeito q[u]igefe (1434 SC 91), revelando o resultado da palatalizaçáo da consoante do radical. Encontra-se num documento de origem periférica e representa apenas 1,4\% do total de ocorrências, constituindo, na língua de Gil Vicente, um traço característico do Viláo, do Ratinho (beirão) e dos pastores (Teyssier 1959: 119) ${ }^{15}$. Referindo que no Norte o $s$ muda para $x$ entre um $i$ oral ou nasal e uma vogal, em certas palavras, José Leite de Vasconcellos exemplifica com as formas quijer, quijeste e quijera, tendo registado quijo (3. ${ }^{a}$ pessoa do singular do pretérito), em Campo de Víboras (zona oriental de Trás-os-Montes) (Vasconcellos 1987: 98, 116).

15. O Autor refere que é difícil de determinar se formas deste tipo provêm diretamente de quige ou se são o resultado de evoluçôes fonéticas mais recentes que transformaram o $s$ em $j, g$ em contato com $i$. Trata-se de formas ainda com vitalidade na linguagem popular, tal como refere José Joaquim Nunes (1989: 330). 


\subsubsection{Pretérito perfeito do verbo Trazer}

Quanto ao perfeito, ao contrário dos documentos editados por Clarinda de Azevedo Maia, na zona que nos ocupa predomina o tipo trouue (variante de trougue, por analogia com houve ${ }^{16}$ ), indiciando que trouxe foi, nesta coleção notarial alcobacense, a variante menos prestigiada ${ }^{17}$. Analisemos os dados constantes da tabela:

\begin{tabular}{llll}
\hline Documentos & Formas & Documentos & Formas \\
\hline 1346 SC 34 & trouxefen; trouxeffen & & \\
& & $1377 \mathrm{Alv} 50$ & trouue \\
& & $1392 \mathrm{MA} 60$ & trouveram; troueftes \\
& & $1396 \mathrm{Ped} 62$ & trouuerẽ \\
1442 SM 97 & t[r]ouxeró & $1442 \mathrm{SM} \mathrm{97}$ & t[r]ouuefem, 2 v. \\
& & $1479 \mathrm{MA} \mathrm{124}$ & trouue \\
\hline
\end{tabular}

Tabela n. ${ }^{\circ}$ 6. Variantes "antigas" e "modernas" das formas do perfeito do verbo trazer

O mesmo constatou Antonino Silva, após ter percorrido um extenso corpus documental: «Pelo nosso lado podemos acrescentar que todas as formas com este radical [TROUX-] são dos finais do século XIV e do século XV (...), mas sempre em minoria relativamente às primeiras [com o radical Trouv-]» (Silva 1998: 112). Os dados por ele observados permitem-lhe concluir:

Esta situação é exactamente oposta aquela que se conhece, e que apresenta Clarinda Maia (...). A partir destes dados procurámos uma explicação que sustentasse as duas opiniōes e parece-nos que ela está na analogia, ou seja, a forma mais escolhida na primeira fase da língua teria sido exactamente a derivada de *TRAXui; contudo, no século XIV o aparecimento de trouve por analogia com houve e sustentado pelas formas também analógicas jouve e prouve teria feito derivar a opção para esta forma (Silva 1998: 112).

São, aliás, formas desse tipo que caracterizam o Perfeito deste verbo, na Carta de Caminha. Aí encontram-se as seguintes formas verbais: trouue, trouuemos, trouuerã, trouueran e trouueram, em inúmeras ocorrências (Almeida \& Carneiro 1996: 222).

Os exemplos aduzidos estão, portanto, conformes com a Gramática de João de Barros, ao apontar como perfeito do verbo trazer a forma trouve (Maia 1997²: 847,

16. Veja-se Vasconcellos (1890-1892a: 271). Curiosamente, em textos galegos da Idade Moderna ("Séculos Escuros"), Varela Barreiro registou as formas troufe e troufer, numa carta (1 Gondomar) (Varela Barreiro 1999: 1060-1061). A forma troufe explica-se, em princípio, por ensurdecimento da labial, pois «v e $f$ são consoantes do mesmo órgão» (Vasconcellos 1890-1892a: 270).

17. Repare-se que no documento 1442 SM 97 desta coleção ainda se regista $t[r]$ oux eró, convivendo, todavia, com t[r]ouuefem (2 v.). 
n. 1). Segundo Clarinda Maia, esta variante tem um carácter nitidamente rústico e popular em Gil Vicente e nos autores da Escola Vicentina (Maia 1997²: 844). Quanto aos dados do seu corpus, e após um percurso feito através de alguns textos, salienta que

parece poder deduzir-se que a norma linguística da época era, quanto a esta particularidade de carácter morfológico, relativamente flutuante: embora ela não rejeitasse totalmente o perfeito trouve, este ia-se tornando cada vez mais um traço correlativo de determinado nível social, a camada popular (Maia 1997²: 847, n. 1).

Recorde-se que a variante trouve surge apenas uma vez na obra de Gil Vicente, no discurso de um camponês, ao lado de 6 ocorrências de trougue, distribuídas pelos discursos de Joane (3 v.), Caterina, Pero Marques e um outro camponês (Teyssier 1959: 114). Esta última variante, eventualmente formada por analogia com prougue (ou simplesmente relacionada com trougue, de trager), nunca foi encontrada na prosa notarial da nossa coleçấo ${ }^{18}$, parecendo-nos ser a que deveria constituir um arcaísmo na linguagem de Gil Vicente, onde é a variante predominante.

No início do século xx, Cândido Figueiredo (1906: 120) exprime-se deste modo, a propósito destas formas:

Entre os antigos, e ainda hoje nalguns pontos da província, nota-se eu trouve, tu trouveste, e nalguns povos da Beira-Baixa ainda se encontra eu trougue, tu trougueste, que também se vê em Gil Vicente e que se relaciona com a antiga fórma trager, por trazer.

O romanceiro popular português conserva ainda estas formas dialetais. A título de exemplo, veja-se esta quadra recolhida numa composição do folclore português, em meados do século $\mathrm{XIX}^{19}$ :

Fostes ao Senhor da Serra,

Nem um anel me trouvestes;

Nem os moiros da moirama

Fazem o que tu fizestes.

18. Varela Barreiro (1999: 1060-1061) apresenta a forma trougo em A história de dom Servando. De acordo com Ferreiro Fernández (1999: 344), em galego, a forma geral moderna traer impôs-se sobre a forma medieval trager, que conviveu com a alternativa traguer, «actualmente sobrevivente fragmentaria en todo o território galego». O Autor refere igualmente que a forma de Pretérito e tempos afins em conformidade com o dialetal traguer sobrevive ainda nas variantes dialetais troguen, trouguera, etc., «mais existen outras moitas formas dialectais minoritárias (troixen, truxen, truien e truen) espalladas pelo território da Galiza» (Ferreiro Fernández 1999: 345).

19. Consulte-se, a este propósito, Prelúdios-Litterários: Jornal academico (UCDigitalis: http://hdl. handle.net/10316.2/35629), p. 87. 
É curioso constatar que nos textos da zona galega, a grande maioria das formas verbais encontradas são de perfeitos com sibilante, com radical Troux- (Varela Barreiro 1999: 1056$)^{20}$, semelhantes às que foram adotadas hoje pela norma do Português. Assim, e tendo em conta os dados da Carta de Caminha, somos de opiniáo que poderá ter havido uma deriva dialetal particularmente acentuada a partir do século xv, a norte e a sul do rio Minho, que desembocou em duas atitudes diferenciadas perante a aceitação das formas com radical sibilante e não sibilante, eventualmente até ao século XviıI.

À falta de dados que possam trazer mais luz sobre a natureza de tal divergência, cabe aqui recordar a riqueza de formas a que se refere José Leite de Vasconcellos:

Lembrando-nos nós que ainda hoje trazo, trouxe, traguer, troufe, etc. pertencem a dialectos diferentes, escusamos de nos admirar de tanta diversidade de formas, pois as leis que regulam os fenómenos linguísticos numa região não são as mesmas que regulam noutra, embora dentro de cada uma tenham geralmente uniformidade» (Vasconcellos 1890-1892a: 271).

\subsubsection{Pretérito perfeito do verbo $(A)$ prazer}

Como se pode verificar na tabela seguinte, as formas com velar $(/ \mathrm{g} /)$ no radical na série do Perfeito prolongaram-se até ao século XVI, tendo sido exclusivas no século XIV:

\begin{tabular}{llll}
\hline \multicolumn{1}{c}{ Documentos } & \multicolumn{1}{c}{ Formas } & Documentos & Formas \\
\hline $1300 \mathrm{Alj} 8$ & p[ro]ugue; p[ro]uguer & & \\
$1307 \mathrm{Alp} \mathrm{13}$ & p[ro]uguer & & \\
$1391 \mathrm{MA} 59$ & p[ro]ugue, 5 v. & &
\end{tabular}

\begin{tabular}{llll} 
& & 1437 Ped 94 & $\begin{array}{l}\text { aprounefe; aprounera } \\
\text { p[ro]une }\end{array}$ \\
1438 Ped 95 & & \\
1455 MA 108 & $\begin{array}{l}\text { ap[r]ouguer } \\
\text { aprouguefSe } \\
\text { prougefSe }\end{array}$ & & \\
1456 MA 109 & 1462 Mai 114 & ap[r]ouer \\
\hline
\end{tabular}

20. O Autor regista, no entanto, as formas com radical não sibilante trouno, trouvo, trouueron, trouverô, trouvera, trouner, trounerdes, trounesse, troubesen, no seguinte corpus: Crónica Troiana, Historia Troyana, Miragres de Santiago, Tratado de Albeitaría por Jordan Rubio, de Calabria, História do Galego-Português e La traducción gallega de la Crónica General y de la Crónica de Castilla (Varela Barreiro 1999: 1056 e nota 7). 


\begin{tabular}{|c|c|c|c|}
\hline Documentos & Formas & Documentos & Formas \\
\hline & & $1462 \mathrm{Alj} 115$ & $p[r]$ oume \\
\hline & & 1467 Mai 117 & $a p[r o] \boldsymbol{u} e \iint e ;$ ap $[r o] \boldsymbol{u} e r, 3 \mathrm{v}$. \\
\hline \multirow[t]{7}{*}{1469 Cel 118} & aprougue; ap[r]ouger & & \\
\hline & & 1477 MA 121 & ap[r]ouuer \\
\hline & & 1478 MA 122 & ap[r]oumer \\
\hline & & 1478 MA 123 & $p[r]$ oumer \\
\hline & & 1479 MA 124 & $p[r]$ oumer; ap [r]ouиer \\
\hline & & 1482 MA 125 & $p[$ ro]uuer \\
\hline & & 1484 MA 127 & $p[r]$ oumer \\
\hline \multirow[t]{3}{*}{1505 MA 138} & aprouger & 1485 MA 128 & $p[r]$ oumer \\
\hline & & 1519 MA 142 & aprouvefe \\
\hline & & 1528 MA 147 & aprouuer \\
\hline
\end{tabular}

Tabela n. ${ }^{\circ}$. Variantes com velar (/g/) no radical e variantes analógicas das formas do Perfeito do verbo (a)prazer

No século $\mathrm{xv}$, a variante dominante é aquela que resultou da ação analógica do perfeito houve. Data de 1437 o primeiro documento quatrocentista ${ }^{21}$ a exibir formas deste verbo, com essa configuração. Embora os dados pareçam indicar que a partir da década de 70 do século XV a regularização das formas de radical deste verbo se tenha efetuado, ainda em 1505 se documenta a forma aprouger.

\subsubsection{Futuro do indicativo do verbo Fazer e derivados (radical FA-/FAZ-) ${ }^{22}$}

Excecionalmente, regista-se a forma de futuro com radical $f a z$ - em vez de $f a$-: «fazerô dello» (1485 MA 128), correspondendo esta forma a 5\% das ocorrências (incluindo formas derivadas). Na mesma década, regista-se faró (1482 MA 125). Tendo em conta que este tipo de formas começa a surgir nos textos apenas a partir de 1380, torna-se difícil averiguar a vitalidade de formas com radical FAZ- na oralidade, uma vez que se trata de uma ocorrência completamente isolada, já em finais do século XV. Apresentamos a seguir as formas com radical FA-, ao longo do corpus:

21. Em outros géneros textuais (textos técnicos, por exemplo), foram encontradas abonaçóes anteriores, remontando mesmo ao século XIII. Em Flores de Dereyto, por exemplo, já se documenta a forma proue, e prouuer regista-se no Foro Real (Gonçalves 2001: 249).

22. A identificação do radical nestas formas não é pacífica: Joseph Piel considera que far é um resto de infinitivo de $3 .^{a}$ conjugaçáo, podendo explicar-se como sendo formado analogicamente a dar. Com efeito, considera o futuro farei (tal como direi e, eventualmente, trarei) um caso diferente dos restantes futuros "por o latim já possuir, segundo parece, os infinitivos de forma divergente DĪRE e FARE» (Piel 1944: 20). 
fara (1459 MA 110), fara (1460 MA 112), fara (1529 MA 148), faram (1479 MA 124, 2 v.), fared[e]s (1392 MA 60), faredes (1380 Alv 52), faredes (1429 MA 88), faredes (1452 MA 106), faredes (1453 MA 107), faredefnolo (1386 MA 56), faredefnolo (1397 MA 63), faredefnolo (1399 MA 66), farees (1452 MA 106), farees (1465 MA 116), faró (1482 MA 125), farrom (1505 MA 138), rrefarees (1452 MA 106).

As abonaçóes citadas parecem, assim, contrariar a afirmação de que «as formas far e dir terão que ser obrigatoriamente posteriores a fazer e dizer» (Silva 1998: 42).

\subsubsection{Regularização analógica no verbo Perder}

Merecem especial referência as formas do presente do conjuntivo do verbo perder. A semivogal das formas latinas do Presente do conjuntivo (< PERDĚAT, por exemplo), tal como da primeira pessoa do singular do Presente do indicativo, afetou a consoante do radical, palatalizando-a. É essa a soluçáo que oferecem os documentos da fase mais antiga, não obstante o advento, já em finais do século XIII, de formas que revelam o processo de transformaçáo analógica ${ }^{23}$. De facto, o documento 1291 Alc 2 é, tanto quanto conhecemos, o mais antigo texto datado a revelar o moderno paradigma, seguindo-se-lhe o galego 1299 P 114, publicado em HGP. É, contudo, interessante, constatar que as antigas variantes persistiam ainda na linguagem dos tabeliães em princípios do século XVI, como revela a abonação registada nesse ano ${ }^{24}$ :

\begin{tabular}{llll}
\hline \multicolumn{2}{c}{ VARIANTES ARCAICAS } & \multicolumn{2}{c}{ VARIANTES MODERNAS } \\
\hline Documento & Formas & Documento & Formas \\
\hline & & 1291 Alc 2 & p[er]q[u]an \\
1321 Alc 17 & p[er]çamos & & \\
1324 Alc 18 & p[er]ça & & \\
1337 Alc 27 & p[er]çam[os] & & p[er]cades \\
& & 1345 MA 33 & p[er]cam \\
& & 1423 MA 83 & perq[ua] \\
& & 1495 MA 134 & p[er]quã, 2 v. \\
1500 MA 136 & pe[r]çam & 1502 MA 137 & p[er]qua \\
& & 1505 MA 138
\end{tabular}

23. Várias têm sido as propostas para a explicação do modelo que terá atuado para a criação de perco e perca. Ver, a esse propósito, Huber (1986: $\$ 378)$.

24. Esta evidência parece relativizar, portanto, a afirmação de Colaço e Cardeira: «tudo indica que no século Xvı o radical PERC- já se tivesse estabelecido na língua como a única forma gramaticalmente aceite para a primeira pessoa do presente do singular do indicativo e todas as pessoas do presente do conjuntivo» (Colaço \& Cardeira 2013: 86). 


\begin{tabular}{llll}
\hline \multicolumn{2}{c}{ VARIANTES ARCAICAS } & \multicolumn{2}{c}{ VARIANTES MODERNAS } \\
\hline Documento & Formas & Documento & Formas \\
\hline & & 1507 MA 139 & p[er]quã \\
\hline
\end{tabular}

Tabela n. ${ }^{\circ}$ 8. Variantes etimológicas e analógicas das formas do verbo perder

Do que parece não haver dúvida é que «o moderno paradigma do presente do indicativo e do presente do conjuntivo tinha já começado a usar-se no século XIII» (Maia 1997²: 801, n. 1), contrariando, assim, a hipótese de Carolina Michaëlis de Vasconcelos, para quem essas formas [modernas] «ainda não tinham vindo à superfície literária no período arcaico» (Maia 1997²: 801, n. 1).

\subsubsection{A primeira pessoa do Presente do indicativo do verbo $S(e) e r$}

Para a primeira pessoa do Presente do Indicativo, foram encontradas as seguintes ocorrências, todas elas evidenciando ainda a evolução etimológica: fóóm (1352 Ped 38), foom (1399 MA 65), foóm (1491 Alj 133) e fJom (1447 Alj 101). Recorde-se que em 1536 é este o depoimento de Fernão de Oliveira: «hũs pronũciã em om como som e outros em ou como sou e outros em ão como são (...)» (Maia $1997^{2}$ 815, n. 2).

De acordo com Joseph Piel «A forma moderna, sou, criou-se, ao que parece, por analogia com estou, vou e dou» ou ainda se pode explicar como procedendo de outra variante arcaica sôo, «em que o $o$ final se pode interpretar como analógico com a desinência regular da $1 .^{a}$ pessoa dos outros verbos, fenómeno que efectivamente se produziu no italiano sono» (Piel 1989: 11). Segundo José Joaquim Nunes, «algumas falas populares conservam ainda as formas arcaicas, som e são» (Nunes 1989ํ: 332, n. 1).

\subsection{Particípios fortes e truncados}

Tal como nos documentos editados por Clarinda de Azevedo Maia, no corpus sob análise existem inúmeras formas fortes (com o lexema do Pretérito perfeito diferente do do Infinitivo), para além dos frequentíssimos dito, feito e escrito:

arroto (1505 MA 138), côclufo (1430 Cós 89), colh[e]ito (1408 MA 71), colbeito (1397 MA 63; 1413 MA 75; 1419 MA 79), colheytas (1304 Alc 10), colheyto (1362 MA 44; 1397 MA 64; 1450 Alv 104), comcluso (1565 Alc 153, 4 v.), concrufo (1460 MA 113), defefa (1482 MA 125; 1490 MA 131, 2 v.), defefas (1495 MA 134; 1502 MA 137; 1507 MA 139; 1528 MA 147), defefsa (1459 MA 110; 1460 MA 112; 1477 MA 121; 1478 MA 122), defeffas (1519 MA 142; 1522 MA 144), deffesas (1500 MA 136), deffesfas (1489 MA 130, 2 v.), deuoluto (1519 MA 142), éleito (1495 
MA 134), emleito (1495 MA 134), efcolheita ${ }^{25}$ (1383 Alj 53), juntos (1391 MA 59; 1459 MA 111; 1465 MA 116; 1505 MA 138; 1522 MA 144; 1527 MA 146; 1529 MA 148), juntoo (1471 MA 119; 1477 MA 121; 1478 MA 122; 1479 MA 124; 1484 MA 126; 1485 MA 128), nado (1502 MA 137), ratas $^{26}$ (1490 MA 131), rrotas (1502 MA 137), rrotos (1529 MA 148), etc.

Para alguns verbos, aparecem, quer os particípios regulares, quer as formas truncadas $^{27}$. Assim, são exclusivas no corpus as formas truncadas dos verbos entregar ${ }^{28}$, limpar ${ }^{29}$, livrar e quitar ${ }^{30}$, sendo que a primeira ocorrência participial do primeiro verbo, localizada no século XIII, exibe a terminaçáo $o$ e não $e$, eventualmente por analogia com as formas regulares do masculino: entrego (1291 Alc 2) ${ }^{31}$. Apresentam-se, a seguir, as restantes formas encontradas no corpus:

ét[re]ges (1328 Alv 20; 1442 SM 97), ẽtregue (1529 MA 148), emt[re]gue (1392 MA 60; 1422 MA 82; 1440 MA 96), ẽmt[re]gues (1428 Alj 86), emtrege (1536 SC 151), emtregueo (1462 Mai 114), ent re]ge (1340 Ped 29; 1343 AM 31; 1343 Cós 32; 1350 AM 36; 1425 MA 82; 1444 Alv 100), entrege (1343 Cós 32; 1491 Alj 132), ent[re]gues (1405 MA 70), ent[re]gue (1425 MA 84), limpo (1460 MA 112), linpo (1426 MA 85; 1465 MA 116; 1478 MA 122; 1484 MA 126; 1489 MA 130; 1527 MA 146), q[ui]te (1375 MA 49), q[u]ites (1315 Alj 15; 1329 Evo 22; 1355 Cel 40; 1422 MA 82), «q[u]it[e] Z ljure» (1448 Ped 102), "q[u]ite e ljure» (1448 Ped 102), «q[u]iti Z ljuri» (1440 MA 96), «q[u]itj Z lyure» (1532 Tur 149), «q[u]ity Z ljure» (1443 Alf 99),

25. No contexto em que surge, trata-se de um particípio nominalizado («dar efcolheita»).

26. Presente na expressão «ratas e gratas».

27. Segundo Anabela Leal de Barros, «esta designação fora, de facto, já usada pelos Romanos para catalogar alguns particípios "curtos", ou seja, sem a terminação -atus, -etus, -utus ou -itus, que, estando "geneticamente" implicados no surgimento de novo verbo (derivado, portanto, do primeiro), com o seu novo particípio regular, acabam por manter-se a par deste como particípio alternativo» (Barros 2000: 219).

28. Recordamos que as abonações de particípios truncados referidas por Clarinda Maia, na variante entrego, datam de 1317, 1333 e 1351, constituindo formas de particípio regular todas as outras referidas. (Maia, 1997²: 753-754). Já Anabela Leal de Barros confirma a tendência observada no nosso corpus: «A forma adjectiva original, entregue, tendo-se, de facto, mantido aliada ao novo verbo - cujo particípio entregado só se regista 2 vezes, no séc. XIV, na regiáo de Lisboa - , surge maioritariamente atestada no corpus, do séc. XIV ao XVI, funcionando como particípio, por vezes mesmo com mudança da terminação invariável (entrego/entrega) para "mais transparentemente" evidenciar o género, ou como forma directamente truncada» (Barros 2000: 210).

29. Os particípios alimpado e alinpado encontram-se, todavia, na Crónica Geral de Espanha de 1344, segundo Anabela Leal de Barros (2000: 65).

30. A forma quitado sofreu um processo de conversão nominal, surgindo como substantivo na expressáo «dar q[u]itado» (1412 Ped 74).

31. Formas deste tipo existem no Português do Brasil a par das outras variantes atemáticas: aceitel aceito, por exemplo. 


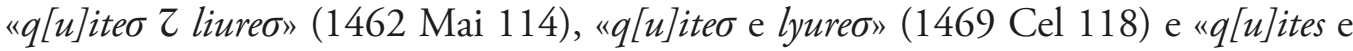
lyures» (1521 Ped 143).

Houve verbos em que se registou variação entre formas de particípio regular e irregular, a partir de cerca do terceiro quartel do século XV, tendo sido a forma truncada aquela que viria a implantar-se no sistema, mas apenas no século Xvi. Referimo-nos ao verbo pagar: é num documento de origem rural, de 1462, que se regista a primeira abonação do particípio truncado: «e derom por bem pagoo he emtregueo» (1462 Mai 114). O nosso corpus revela que no século Xvi apenas existe a nova variante:

«pagas em cada hũu anno» (1507 MA 139), "pagos per dia de Natall» (1505 MA 138), «sob pena de lhe ser pago o dito dinhejro» (1532 Tur 149),

enquanto que os documentos publicados por Clarinda Maia falam a favor da sua atualização desde a primeira metade do século XIV (Maia 1997²: 754) ${ }^{32}$.

Apresentam-se a seguir os particípios regulares encontrados nesta coleção:

pagad[os] (1453 MA 107), pagad[oб] (1478 MA 123; 1479 MA 124), pagada (1388 MA 57; 1399 MA 65; 1405 MA 70; 1428 MA 87; 1434 SC 91; 1438 Ped 95; 1440 MA 96; 1452 MA 106; 1453 MA 107; 1465 MA 116; 1484 MA 126), pagadas (1442 MA 98), pagado (1440 MA 96, 3 v.; 1443 Alf 99; 1451 MA 105; 1452 MA 106, 2 v.; 1453 MA 107, 3 v.; 1459 MA 110, 2 v.; 1477 MA 121; 1478 MA 122; 1478 MA 123; 1479 MA 124; 1489 MA 130, 2 v.; 1495 MA 134), paguada (1402 MA 67; 1412 Ped 74), paguado (1402 MA 67; 1422 MA 82; 1425 MA 84; 1429 MA 88).

Em outros casos, há indícios de ter havido variação entre particípios regulares e truncados, na mesma década, mas estes últimos não se implantaram, eventualmente por se tratar de um lexema pouco usado na língua comum. É o caso do verbo outorgar, que conheceu a variante outo[r]ga ${ }^{33}$, tal como nos mostra um documento de 1469, também de origem rural (Cela):

32. Também Anabela Leal de Barros testemunha que «não existem, pois, em todo o corpus atestaçóes de pago anteriores ao século xiv, e neste século todas surgem apenas a Norte». Quanto às abonaçóes da zona de Lisboa, encontram-se duas no século xv e duas no século xvi (Barros 2000: 224-225). Esta constataçáo vai, assim, ao encontro dos nossos dados, indiciando uma propensão para os particípios fracos, na zona onde se viria a constituir a norma.

33. Dado o seu carácter excecional ao longo do corpus, não se exclui a hipótese de constituir um lapso do tabelião. Lembre-se, todavia, que estes textos eram muitas vezes escritos por "mãos inábeis", podendo conter «dados linguísticos não normalizados, interessantes por revelarem insuspeitadas dimensōes da variação linguística» [Gramática do Português (Castro, Ivo, Cap. 1: "Formação da Língua Portuguesa") 2013: 13]. 
«Fecta e outo[r]ga foy ẽ o dicto logo da dicta Çella» (1469 Cel 118).

Apresentam-se, a seguir, os particípios de tipo regular:

outo[r]gad[oo] (1459 MA 110; 1471 MA 119; 1477 MA 121; 1478 MA 123; 1479 MA 124), outorgada (1484 MA 127), outorgadas (1459 MA 111), outo[r]gada (1459 MA 110), outorgado (1297 Alc 5; 1300 Alj 8; 1306 Cós 12; 1405 MA 70; 1447 Alj 101), outo[r]gado (1505 MA 138; 1443 Alf 99), outorguada (1462 Mai 114).

Ao longo do corpus, os verbos empregar e ganhar/gançar apenas exibem o particípio regular, não se tendo registado qualquer inovação, eventualmente para não se proporcionar a confusão com as formas verbais de primeira pessoa (eu emprego, eu ganho, por exemplo):

ẽp[re]gado (1343 AM 31, 2 v.), enp[re]gado (1343 AM 31), gãâçados (1397 MA 63; 1397 MA 64; 1399 MA 66; 1409 MA 72; 1413 MA 75), gáánçados (1359 MA 42), gaançados (1408 MA 71; 1410 MA 73), Gaanhada, top. (1399 MA 65), gáánhados (1345 MA 33; 1375 MA 48; 1386 MA 55), gaanhados (1386 MA 56; 1388 MA 58; 1426 MA 85), gaçados (1450 Alv 104), gamçados (1522 MA 144; 1527 MA 146), gançados (1392 MA 60; 1465 MA 116; 1528 MA 147), guanhada (1451 MA 105), guááç̧ados (1403 MA 69), guãçados (1422 MA 82), guãnçados (1423 MA 83), guanhadas (1428 MA 87), guanhados (1416 MA 78).

Finalmente, algumas abonaçóes apresentadas por Anabela Leal de Barros e Said Ali, quando confrontadas com os nossos dados, levam a crer que as formas truncadas e fortes dos particípios revelariam uma tendência mais popular ${ }^{34}$, enquanto as formas fracas e não truncadas se documentam abundantemente nos textos literários. Aquela autora apresenta, por exemplo, as formas entregado nas Cantigas de Santa Maria, na Demanda do Santo Graal e nos Lusíadas; quanto a alimpadolalinpado, regista-a na

34. No português oral do Brasil verifica-se uma grande abertura dos falantes a formas resultantes de truncamento, o que poderá atestar a continuidade de uma tendência antiga registada na língua oral da Metrópole. Segundo Rita Marquilhas, «exemplo flagrante de como é imprevisível o desfecho deste fenómeno é o facto de o espanhol contemporâneo ter os seus particípios duplos a desaparecerem num sentido exatamente contrário ao do português, ou seja, em benefício dos particípios fracos, que são cada vez em maior número no discurso coloquial (...). Mesmo as variedades europeia e brasileira do português diferem em relação aos verbos que admitem particípios duplos (...)» [Gramática do Português (Marquilhas, Rita, Cap. 2: "Fenómenos de mudança na história do português") 2013: 34, n. 17. É, de facto, complexo e imprevisível o rumo do fenómeno na modalidade americana do português, pois, se por um lado, a gramática do PB conserva particípios como ganhado, gastado e pagado, por outro, prevê particípios irregulares inexistentes no PE, tal como pegalpego (de pegar). 
Crónica Geral de Espanha de 1344 e na Crónica da Ordem dos Frades Menores (Barros 2000: 61, 72, 79, 87, 88 e 92), enquanto que nos documentos em análise aparecem sempre na variante truncada. Por outro lado, Said Ali $\left(1966^{6}: 128\right)$ refere a forma emllegido no discurso de Fernão Lopes («FERNÃO LOPES, ao descrever a eleição do mestre de Avis para rei de Portugal, emprega o particípio muitas vêzes e sempre com terminação regular»), particípio que na prosa notarial analisada surge sempre na forma forte.

\section{Conclusões}

Vimos como, mesmo num subsistema tão específico como é a morfologia verbal, houve variadíssimas mudanças linguísticas com caráter multissecular, cuja fronteira é difícil delimitar. É, no entanto, possível delinear uma gradação, de acordo com o grau de aceitação e o prestígio das novas variantes ou, simplesmente, a celeridade com que elas se implementaram na escrita. $\mathrm{O}$ período compreendido entre o último quartel do século XIV e meados do século xv foi, como se viu, de intensa elaboração da língua, confirmando, assim, as conclusóes que temos vindo a apresentar relativamente a inúmeros outros fenómenos nas diversas áreas de descrição ${ }^{35}$. Apresenta-se o que é possível concluir a partir dos documentos: os termos a quo e ad quem de alguns fenómenos analisados:

35. Também relativamente às formas de pretérito e tempos afins do verbo irregular fazer com vogal radical /i/, fenómeno que já analisámos (Carvalho 2015: 54), e apesar da falta de representatividade estatística em virtude da ocorrência isolada das formas em alguns documentos, é possível inferir a mesma constataçáo cronológica. Apresentamos a seguir as percentagens de formas com vogal $i$ no radical, em cada documento: 1386 (14\%), 1405 (33\%), 1437 (50\%), 1438 (100\%), 1465 (100\%). Ao contrário do que seria expectável estatisticamente, um documento de 1565 volta a apresentar apenas $50 \%$ de inovaçóes, o que vem provar que uma periodização da língua oral não pode confundir-se com a periodização da língua escrita. 


\begin{tabular}{|c|c|c|c|}
\hline Morfologia Verbal & INOVAÇÃO & $\begin{array}{c}\text { SOBREVIVÊNCIA } \\
\text { DA VARIANTE } \\
\text { ARCAICA } \\
\end{array}$ & $\begin{array}{c}\text { MOMENTO PROVÁVEL DA } \\
\text { MUDANÇA }\end{array}$ \\
\hline \multicolumn{4}{|l|}{ PARTICÍPIOS EM -udo } \\
\hline (1. ${ }^{\circ}$ grupo) & 1388 & 1455 & $2 .^{\circ}$ quartel do séc. $\mathrm{XV}$ \\
\hline (2. ${ }^{\circ}$ grupo $)$ & 1388 & 1482 & $3 .^{\circ}$ quartel do século $\mathrm{xV}$ \\
\hline (3. ${ }^{\circ}$ grupo $)$ & 1541 & $?$ & $?$ \\
\hline Morfema número-pessoal -des & 1451 & 1478 & Cerca de 1450 \\
\hline $\begin{array}{l}\text { Verbos incoativos (des)perecer } \\
\text { e merecer }\end{array}$ & 1405 & 1391 & Último quartel do século XIV \\
\hline $\begin{array}{l}\text { Radical incoativo CONHOSC- } \\
\text { (conhoscer > conhocer) }\end{array}$ & 1321 & 1399 & Último quartel do século XIV \\
\hline $\begin{array}{l}\text { Verbo incoativo conhocer ou } \\
\text { derivados e dissimilaçáo vocálica } \\
\text { (conhocer> conhecer) }\end{array}$ & 1315 & 1456 & Cerca de 1450 \\
\hline $\begin{array}{l}\text { Apócope de }-e \text { na } 3 .^{\mathrm{a}} \text { pessoa do } \\
\text { Presente do indicativo de trazer: } \\
\text { trage > traz }\end{array}$ & 1416 & 1375 & Último quartel do século XIV \\
\hline $\begin{array}{l}\text { Regularização consonântica do } \\
\text { radical (trager): TRAG- (com en- } \\
\text { travamento palatal sonoro)/TRAZ- } \\
\text { (com fricativa alveolar sonora) }\end{array}$ & 1414 & 1442 & Último quartel do século XIV \\
\hline $\begin{array}{l}\text { Pretérito perfeito de Trazer: TROUX- } \\
\text { (de TRAXUITT)/TROUV- }\end{array}$ & 1346 & $1479^{*}$ & $?$ \\
\hline $\begin{array}{l}\text { Pretérito perfeito de aprazer: } \\
\text { (A)PROUGU-/(A)PROUV- }\end{array}$ & 1437 & 1505 & $3 .^{\circ}$ quartel do século XV \\
\hline $\begin{array}{l}\text { Futuro imperfeito do verbo fazer: } \\
\text { FA-36/FAZ- }\end{array}$ & $1380^{*}$ & 1485 & $?$ \\
\hline $\begin{array}{l}\text { Regularização analógica no verbo } \\
\text { perder: PERÇ-/PERC- }\end{array}$ & 1291 & 1500 & Século XVI \\
\hline $\begin{array}{l}\text { Primeira pessoa do Presente do } \\
\text { indicativo do verbo Seer (foom) }\end{array}$ & - & $1491^{*}$ & $?$ \\
\hline $\begin{array}{l}\text { Particípios fortes de eleger, quitar, } \\
\text { limpar, livrar, entregar, romper, juntar }\end{array}$ & & & $\begin{array}{l}\text { Usados de modo exclusivo } \\
(1289-1565)^{37}\end{array}$ \\
\hline Particípio forte de pagar (pago) & 1462 & 1495 & A partir do século xvI \\
\hline
\end{tabular}

Tabela n. ${ }^{0}$ 9. Síntese das cronologias dos vários fenómenos de mudança $a^{38}$

36. Segundo Ferreiro Fernández, «estas formas pódense explicar foneticamente por meio dun processo de asimilación regressiva -z'r- >-r-» e, por isso, a partir de uma base *FARE (Ferreiro Fernández 1999: 328). 37. Trata-se, eventualmente, de um conjunto de verbos que evoluíram ininterruptamente de particípios curtos já existentes em Latim.

38. O asterisco junto das datas significa que não possuímos dados anteriores ou posteriores à data assinalada. 
A título exemplificativo, repare-se que o português e o galego partilharam, desde o século XIII, o desaparecimento do $d$ intervocálico das formas verbais de P5, tendo sido, todavia, distinta a avaliação social (a norte e a sul do rio Minho) da perda ou manutençáo desta consoante, a partir do século xv. Por outro lado, parece ter partilhado até bastante tardiamente a forma etimológica de $1 .{ }^{\mathrm{a}}$ pessoa do Presente do indicativo do verbo ser (sóm/foom), pois não se vislumbra qualquer forma analógica no escopo cronológico desta coleçáo (1289-1565). Partilhou com o espanhol, apenas durante o século XIV, o radical com -SC- dos verbos incoativos perecer e merecer, que esta língua ainda conserva. Por outro lado, prolongou até meados do século seguinte a partilha da forma etimológica conhocer, sem dissimilação vocálica, tal como existe atualmente no espanhol. Em ambos os casos, apresentam o galego e o português soluçóes mais inovadoras, por vezes alicerçadas na ação niveladora da analogia, regularizadora, mas irregular. Por outro lado, o português e o galego partilham ainda atualmente a palatalizaçáo da consoante do radical na forma de Pretérito perfeito do verbo pôr (pus, port.; puxen, gal.; puse, esp.), sendo que a vogal final ainda se mantém no galego. $\mathrm{O}$ infinitivo trager e a forma de Perfeito trouveste, com bastante aceitação ao longo do português arcaico, ainda existiam em certas zonas do país e no romanceiro popular no século xx. Ao longo de toda a Idade Média, parece que as formas truncadas dos particípios passados angariaram menos prestígio do que as formas regulares, ao contrário do que parece ser a tendência no Português europeu contemporâneo, não obstante tratar-se (em alguns casos) de um processo de mudança ainda em curso.

Pretende-se, com os dados apresentados neste trabalho, dar um pequeno contributo na demonstração de que há um passado comum entre as línguas e variedades ibero-românicas, que não deve ser negligenciado. Esta constatação aponta para a inevitável necessidade de, de futuro, adotar uma perspetiva sociolinguística em estudos de comparação de línguas nesta área geográfica.

\section{Agradecimentos}

Agradeço à equipa editorial da revista $E L G$ bem como aos pareceristas anónimos que fizeram a apreciação crítica deste artigo, pelos seus comentários, sugestóes e correçôes. Qualquer erro, lapso ou imprecisão que possam eventualmente subsistir são da minha inteira responsabilidade. 


\section{Bibliografia}

Ali, Said. 1966. Dificuldades da língua portuguêsa. 2. ${ }^{\text {a }}$ ed. Rio de Janeiro: Livraria Acadêmica.

Almeida, Norma Lúcia F. de \& Zenaide de Oliveira N. Carneiro. 1996. Verbos de padrão especial: um breve estudo descritivo e comparativo. Em Rosa Virgínia Mattos e Silva (Org.). A carta de Caminha. Testemunho lingüistico de 1500. 213-236. Salvador: Universidade Estadual de Feira de Santana/ Empresa Gráfica da Bahia e Edufa.

Barros, Anabela Leal de. 2000. O particípio passado. Aspectos da sua morfologia do século XIII ao século Xvi. (Dissertação de mestrado apresentada à Faculdade de Letras da Universidade de Lisboa. Inédita).

Buzaglo Paiva Raposo, Eduardo, Maria Fernanda Bacelar do Nascimento, Maria Antónia Coelho da Mota, Luísa Segura \& Amália Mendes (orgs.). 2013. Gramática do Português. I, p. 7-14 e 17-45. Lisboa: Fundação Calouste Gulbenkian.

Carvalho, Maria José. 2013. Contributo para o estudo da evolução das terminaçóes nasais portuguesas (sécs. XIII-XVI). Em Emili Casanova Herrero e Cesáreo Calvo Rigual (Eds.), Actas del XXVI Congreso Internacional de Lingüistica y de Filología Románicas, Valencia 2010, vol. I. 567-577. Berlin/ Boston: Walter de Gruyter.

Carvalho, Maria José. 1999-2000. Cronologia(s) da substituição da terminação participial -udo por -ido, no português medieval (sécs. XIII-XVI). Revista Portuguesa de Filologia 23, p. 381-409.

Carvalho, Maria José. 2017. Documentação medieval do mosteiro de Santa Maria de Alcobaça. Edição, com introdução e notas de aparato crítico (= Verba, Anexo 74). 255 pp. Universidade de Santiago de Compostela: Servicio de Publicacións e Intercambio Científico. (Trata-se do corpus, com alteraçóes pontuais, inserido na dissertação de doutoramento da Autora, apresentada à Faculdade de Letras da Universidade de Coimbra, em 2006). https://www.unebook.es/ es/ebook/documentaco-medieval-do-mosteiro-de-santa-maria-de-alcobaca_E0002619902. $(11 / 11 / 2018)$.

Carvalho, Maria José. 2006. Documentação medieval do mosteiro de Santa Maria de Alcobaça (sécs. XIII-XVI). Edição e estudo linguístico. (Dissertação de doutoramento em Linguística Portuguesa apresentada à Faculdade de Letras da Universidade de Coimbra. Parcialmente inédita).

Carvalho, Maria José. 1996. Do Português arcaico ao Português moderno. Contributos para uma nova proposta de periodização. (Dissertação de mestrado em Linguística Portuguesa, elaborada no âmbito do Programa Praxis XXI e apresentada à Faculdade de Letras de Coimbra. Inédita).

Carvalho, Maria José. 2000. O morfema - des na história da língua portuguesa: uma abordagem segundo a metodologia da Sociolinguística histórica. Em Annick Englebert, Michel Pierrard, Laurence Rosier \& Dan Van Raemdonck (Eds.), Actes du XXIIème Congrès International de Linguistique et de Philologie romanes (Bruxelles, 23-29 juillet 1998). Vol. II. 65-74. Tübingen: Max Niemeyer Verlag.

Carvalho, Maria José. 2002. Periodização da língua portuguesa num contexto social: uma contribuição para a Sociolinguística histórica. Revista Galega de Filoloxía 3, p. 11-27 https://ruc.udc. es/dspace/bitstream/handle/2183/2593/RGF-3-1-def.pdf;jsessionid=EECBA6E2402559762C6FACB6CF9637DA?sequence=1). (11/11/2018).

Carvalho, Maria José. 2011. Revisitando o morfema -des: cenário para a sua evolução. Em Gonçalves, Filomena (Ed.), 500 anos de Lingua Portuguesa no Brasil, I. 531-550. Lisboa: Cosmos. 
Carvalho, Maria José. 2015. Sobre as origens dos valores de /e/ átono em posição medial no Português europeu e brasileiro. Revista Galega de Filoloxía 16, p. 43-73. DOI: 10.17979/rgf.2015.16.0.1378. (22/11/2018).

Carvalho, Maria José. 2003. The transition from early to modern Portuguese. An approach from historical sociolinguistics. E Barry J. Blake \& Kate Burridge (Ed.), Historical Linguistics 2001. Selected Papers from the 15th International Conference on Historical Linguistics, Melbourne, 13-17 August 2001. 59-69. Amsterdam / Philadelphia: John Benjamins Publishing Company. (https:// doi.org/10.1075/cilt.237.06car). (11/11/2018).

Coelho, Eduardo. 1859. A manhã na minha Terra [dirigido ao seu amigo Vieira da Silva]. Prelúdios-Litterários: Jornal académico (Lisboa, Janeiro de 1859). Coimbra: Imprensa da Universidade, 87. UCDigitalis: http://hdl.handle.net/10316.2/35629. (26/10/2018).

Colaço, Maria Joáo \& Cardeira, Esperança. 2013. Menço ou minto? Regularizaçáo de paradigmas verbais. Diacritica 27/1, p. 69-94.http://www.scielo.mec.pt/scielo.php?script=sci_arttext\&pi$\mathrm{d}=$ S0807-89672013000100003\&lng=pt\&nrm=iso. $(16 / 07 / 2018)$.

Ferreiro Fernández, Manuel. 19994. Gramática histórica galega. 1. Fonética e Morfosintaxe. Santiago de Compostela: Laiovento.

Figueiredo, Cândido de. 1906. Falar e escrever. Novos estudos práticos da língua portuguesa ou Consultório popular de enfermidades da linguagem, 2. a série. Lisboa: Livraria Clássica Editora. https:// archive.org/details/falareescrevevrno00figugoog?q=trouvestes. Digitalizado pela Biblioteca da Universidade de Harvard. (3/07/2018).

Gonçalves, M.a Fernanda Moreira. 2001. Morfologia verbal do galego-português: a acção niveladora da analogia. En Actas do XVI Encontro Nacional da Associação Portuguesa de Linguística. 241-253. Lisboa: Associação Portuguesa de Linguística. https://apl.pt/wp-content/ uploads/2017/12/2000-20.pdf. (11/11/2018).

Huber, Joseph. 1986. Gramática do Português antigo. Lisboa: Fundação Calouste Gulbenkian. (trad. do original alemáo: Altportugiesisches Elementarbuch).

Maia, Clarinda de Azevedo. 1997. História do Galego-Português. Estado linguístico da Galiza e do noroeste de Portugal desde o século XIII ao século XVI (Com referência à situação do Galego moderno). 2. ${ }^{\text {a }}$ ed. Lisboa: FCG/ JNICT. https://digitalis.uc.pt/pt-pt/livro/hist\%C3\%B3ria_do_galego_portugu\%C3\%AAs_estado_lingu\%C3\%ADstico_da_galiza_e_do_noroeste_de_portugal_desde_o. (26/07/2018).

Maia, Clarinda de Azevedo. 1994. O Tratado de Tordesilhas. Algumas observaçôes sobre o estado da língua portuguesa em finais do século xv. Biblos. Revista da Faculdade de Letras 52, 33-91.

Mariño Paz, Ramón. 2005. Cronoloxía da desaparición dos particípios verbais terminados en -udo en fontes galegas medievais. Em Rio-Torto, Graça Maria de Oliveira e Silva, Olívia Maria Figueiredo, \& Fátima Silva (Orgs.), Estudos em homenagem ao Professor Doutor Mário Vilela. vol. II, p. 795-809. Porto: Faculdade de Letras da Universidade do Porto. http://ler.letras.up.pt/uploads/ ficheiros/4607.pdf. (4/10/2018).

Mariño Paz, Ramón. 1992. O sufixo número-personal da P5 en galego: o retrocesso moderno da solución cantás. Cadernos de Lingua, 5 (1. ${ }^{\circ}$ semestre), p. 75-97. https://dialnet.unirioja.es/ejemplar/407294. (8/10/2018).

Mariño Paz, Ramón. 2014. Traxectoria histórica dos resultados galegos do sufixo número-persoal latino -ťss. Em Leticia Eirín García \& Xoán López Viñas (eds.), Lingua, texto, diacronia. Estudos 
de lingüistica histórica. (= Revista Galega de filoloxía, monografía 9), 257-290. http://illa.udc.es/ rgf/pdf/mon_9.pdf. (11/11/2011).

Mariño Paz, Ramón. 2016. Traxectoria histórica dos resultados galegos do sufixo número-persoal latino -TE (P5 do imperativo). Em Alexandre Rodríguez Guerra (ed.), Lingüística histórica e dialectoloxía: coordenadas do cambio lingüístico. 141-162. Vigo: Servizo de Publicacións da Universidade de Vigo.

Nunes, José Joaquim. 1989. Compêndio de gramática histórica portuguesa (Fonética e Morfologia). 9.a ed. Lisboa: Clássica Editora.

Piel, Joseph. 1944. A flexão verbal do português (Estudo de morfologia histórica). Biblos. 20, p. 359-404. (O artigo foi incluído na coletânea do autor Estudos de linguistica histórica galego-portuguesa. 213-244. Lisboa: Imprensa Nacional - Casa da Moeda, 1989). http://cvc.instituto-camoes.pt/ hlp/biblioteca/flexao_verbal.pdf, 29 pp. (BN: L41496V). (27/07/2018).

Silva, Antonino da Conceição de Almeida e. 1998. O sistema verbal do português arcaico. O papel da analogia na regularização dos paradigmas verbais do português arcaico da segunda fase. (Dissertaçáo de Mestrado em Linguística Portuguesa, apresentada à Faculdade de Letras da Universidade de Coimbra. Coimbra: Faculdade de Letras. Iinédita).

Teyssier, Paul. 1959. La langue de Gil Vicente. Paris: Klincksieck.

Varela Barreiro, Xavier. 1999. A evolución do radical dos pretéritos irregulares sigmáticos, em Rosario Álvarez \& Dolores Villavedra (eds.), Cinguidos por unha arela común. Homenaxe ó Profesor Xesús Alonso Montero. Tomo I: Semblanza e Creación / Lingua / Historia, Cultura e Sociedade. 1047-1072. Universidade de Santiago de Compostela: Servicio de Publicacións e Intercambio Científico.

Vasconcellos, José Leite de. 1987. Esquisse d’une Dialectologie Portugaise. Lisboa: Instituto Nacional de Investigação Científica. (3.a ediçáo por Maria Adelaide Valle Cintra).

Vasconcellos, José Leite de. 1890-1892a. Etymologias portuguesas: trazer e traguer. Em Revista Lusitana 2, p. 269-271.

Vasconcellos, José Leite de. 1890-1892b. Notas philologicas: Trager. Revista Lusitana 2, p. 349. 